\title{
Experimental and Modelling of Alkali-Activated Mortar Compressive Strength Using Hybrid Support Vector Regression and Genetic Algorithm
}

\author{
Khaled A. Alawi Al-Sodani ${ }^{1}\left(\mathbb{D}\right.$, Adeshina Adewale Adewumi 1,2 ${ }^{(D}$, Mohd Azreen Mohd Ariffin 2,3, \\ Mohammed Maslehuddin ${ }^{4}$, Mohammad Ismail ${ }^{2}$, Hamza Onoruoiza Salami ${ }^{5}$, Taoreed O. Owolabi ${ }^{6, *}$ and \\ Hatim Dafalla Mohamed ${ }^{7}$
}

1 Department of Civil Engineering, University of Hafr Al Batin, Hafar Al-Batin 31991, Saudi Arabia; kalsodani@uhb.edu.sa (K.A.A.A.-S.); walasco2010@gmail.com (A.A.A.)

2 School of Civil Engineering, Faculty of Engineering, Universiti Teknologi Malaysia, UTM Johor Bahru 81310, Malaysia; mohdazreen@utm.my (M.A.M.A.); mohammad@utm.my (M.I.)

3 Forensic Engineering Centre, Institute for Smart Infrastructure \& Innovation Construction, School of Civil Engineering, Faculty of Engineering, Universiti Teknologi Malaysia, UTM Johor Bahru 81310, Malaysia

4 Integrated Center for Research on Construction and Building Materials, King Fahd University of Petroleum and Minerals, Dhahran 31261, Saudi Arabia; muddin@kfupm.edu.sa

check for updates

Citation: Al-Sodani, K.A.A.;

Adewumi, A.A.; Mohd Ariffin, M.A.; Maslehuddin, M.; Ismail, M.; Salami, H.O.; Owolabi, T.O.; Mohamed, H.D. Experimental and Modelling of Alkali-Activated Mortar Compressive Strength Using Hybrid Support Vector Regression and Genetic Algorithm. Materials 2021, 14 , 3049. https://doi.org/ 10.3390/ma14113049

Academic Editors: Paola Antonaci, Jean-Marc Tulliani and Paola Antonaci

Received: 21 April 2021

Accepted: 28 May 2021

Published: 3 June 2021

Publisher's Note: MDPI stays neutral with regard to jurisdictional claims in published maps and institutional affiliations.

Copyright: (C) 2021 by the authors Licensee MDPI, Basel, Switzerland. This article is an open access article distributed under the terms and conditions of the Creative Commons Attribution (CC BY) license (https:/ / creativecommons.org/licenses/by/ $4.0 /)$.
5 College of Computer Science and Engineering, University of Hafr Al Batin, Hafar Al-Batin 31991, Saudi Arabia; hamzaosalami@gmail.com

6 Physics and Electronics Department, Adekunle Ajasin University, Akungba Akoko 341112, Ondo State, Nigeria

7 Core Research Facilities, King Fahd University of Petroleum and Minerals, Dhahran 31261, Saudi Arabia; dmhatim@kfupm.edu.sa

* Correspondence: owolabitaoreedolakunle@gmail.com; Tel.: +234-8067226208

Abstract: This paper presents the outcome of work conducted to develop models for the prediction of compressive strength (CS) of alkali-activated limestone powder and natural pozzolan mortar (AALNM) using hybrid genetic algorithm (GA) and support vector regression (SVR) algorithm, for the first time. The developed hybrid GA-SVR-CS1, GA-SVR-CS3, and GA-SVR-CS14 models are capable of estimating the one-day, three-day, and 14-day compressive strength, respectively, of AALNM up to $96.64 \%, 90.84 \%$, and $93.40 \%$ degree of accuracy as measured on the basis of correlation coefficient between the measured and estimated values for a set of data that is excluded from training and testing phase of the model development. The developed hybrid GA-SVR-CS28E model estimates the 28-days compressive strength of AALNM using the 14-days strength, it performs better than hybrid GA-SVR-CS28C model, hybrid GA-SVR-CS28B model, hybrid GA-SVR-CS28A model, and hybrid GA-SVR-CS28D model that respectively estimates the 28-day compressive strength using three-day strength, one day-strength, all the descriptors and seven day-strength with performance improvement of $103.51 \%, 124.47 \%, 149.94 \%$, and $262.08 \%$ on the basis of root mean square error. The outcome of this work will promote the use of environment-friendly concrete with excellent strength and provide effective as well as efficient ways of modeling the compressive strength of concrete.

Keywords: compressive strength; natural pozzolan; genetic algorithm; limestone powder; support vector regression

\section{Introduction}

Concrete is the backbone of our built-environment, especially in urban areas [1]. The construction of infrastructures, such as bridges, roads, dams, tunnels, high-rise buildings, dams, airports, seaports, power plants, seawalls, wastewater plants, freshwater plants and dykes for social and economic benefits consumed roughly 35 billion tons of concrete [2]. This is generally due to its favorable compressive strength, durability, versatility, global availability of the constituent materials, high fire-resistance, and relatively low cost [3]. 
The world production of Ordinary Portland cement (OPC), the main binding component in concrete was estimated to be 4.6 billion tons in the year 2015 with a projection of fourfold increase by 2050 [4]. However, the OPC calcination process significantly leads to the emission of $5-8 \%$ of global $\mathrm{CO}_{2}$ into the atmosphere which has greatly contributed to the depletion of earth's ozone layer [5,6]. Demand-pull by the low carbon-conscious market has gravitated attention to the use of alkali-activated materials (AAM) or geopolymer concrete in recent years as an alternative to OPC [7].

AAM is a system formed by the reaction of soluble alkaline activator and aluminosilicate precursors [8]. AAM is classified into low calcium or geopolymer (fly ash, metakaolin, and natural pozzolans) and high calcium (blast furnace slag) binders. The main products in low binder AAM could be mainly potassium/sodium silicate hydrate with impregnation of alumina (NASH and KASH) within the formation. In high calcium binders, such as blast furnace slag, that are synthesized with a mild alkali, the main product is calcium alumina silicate hydrate (CASH) [9]. AAM has been identified as an eco-efficient and economically-viable alternative for replacing OPC due to its excellent strength, thermal resistance and low permeability $[8,10]$. AAM is gaining wide acceptance as a component of a sustainable cementitious binder system. It has a wide range of application in precast concrete in which the alkaline activators can be handled appropriately and the curing methods can be controlled and also it can be used for in-situ construction. The world's largest geopolymer concrete project was carried out by using $40,000 \mathrm{~m}^{3}$ of geopolymer concrete for the construction of heavy-duty pavement at the Brisbane west well camp airport in Australia [11]. Additionally, several road projects were constructed using geopolymer by VicRoads state agency in Australia [12]. Furthermore, several applications and standardization of AAM are being done in Russia, Ukraine, South Africa, Netherlands, UK, and the USA, among others [13-15]. Many researchers have successfully synthesized alkali-activated mortars and concretes experimentally from natural raw materials, such as natural pozzolan (NP) $[9,16,17]$, agricultural waste materials, such as rice husk ash [18], palm oil fuel ash (POFA) [18-22], or industrial waste, such as silico-manganese slag (SiMn) [23], ground granulated blast furnace slag (GGBFS) [23-25], fly ash (FA) [26], silica fume (SF) [26,27], coal bottom ash [28], paper sludge ash [29], and mine tails [8] with aluminosilicate components.

The determination of material properties for the design of civil engineering structures is of great significance to the construction industry. The compressive strength (CS) of AAM is one of the key mechanical properties that dictates its suitability for structural purposes. The CS of alkali-activated mortar (AAMT) is a function of many parameters, such as the chemical composition of the primary or base materials (precursor), sodium hydroxide molarity $(\mathrm{NH})$, curing temperature, sodium silicate to sodium hydroxide (NS/NH) ratio or silica modulus, alkali to binder ratio [NS $+\mathrm{NH}$ )/BD], fine aggregate to binder ratio (FA/BD), water to binder ratio (W/BD), and the curing temperature and duration $[9,20,30]$. The synthesis of AAMT by using the traditional laboratory procedures is laborious, expensive, and time-consuming. This is because the process involves the preparation, curing, and testing of several specimens [31]. Thus, there is a need to develop an alternative procedure that can eliminate the limitations of the traditional methods. This work models the compressive strength of AAMT prepared with natural pozzolan (NP) and limestone powder waste (LSPW) using hybrid support vector regression and genetic algorithm for the first time.

Support vector regression (SVR) is a machine learning algorithm that is capable of relating descriptors to the desired target through pattern acquisition and generation of support vectors $[32,33]$. It has been extensively applied in many real-life applications due to its unique features, such as strong mathematical background, non-convergence to a local minimum, and excellent predictive strength in the presence of few data-points and descriptive features [34-39]. The user-defined parameters in SVR algorithm, such as regularization factor, epsilon, hyper-parameter lambda, kernel option, and kernel function 
play a significant role when it comes to model performance [40]. These hyper-parameters are evolutionarily optimized in this research work using a genetic algorithm.

Despite the inevitability of concrete in construction industries, the environmental danger of conventional ordinary Portland cement is of serious concern which necessitates urgent attention to alkali-activated materials as the potential alternative to ordinary Portland cement due to their environmental-friendliness, excellent compressive strength, and low permeability. In order to predict the compressive strength (CS) of AAMs without waste of precious time and other valuable resources while the experimental precision is preserved, this present work models the compressive strength of alkaline activated limestone powder and natural pozzolan mortar (AALNM) using hybrid genetic algorithm (GA) and support vector regression (SVR) algorithm, for the first time. The outputs of the developed models are validated using experimental data of the prepared AALNM specimens with different mixture proportions and compositions. The outcome of the modeling and simulation of the compressive strength of AALNM will facilitate the quick estimation of the compressive strength of AALNM system to a high degree of precision, while it saves valuable time and other material resources.

\section{Description of the Mathematical Background of the Proposed Hybrid Models}

This section presents the mathematical formulation of support vector regression as well as genetic algorithm.

\subsection{Formulation of Support Vector Regression Algorithm}

Support vector regression (SVR) is a machine learning algorithm developed by Vapnik [41,42]. It is the regression counterpart of support vector machine, which is used for solving classification problems. SVR has been known to produce good results even when there are few training samples [31,43]. Let $\left\{\left(x_{1}, y_{1}\right),\left(x_{2}, y_{2}\right), \ldots\left(x_{n}, y_{n}\right)\right\}$ be a set of $\mathrm{n}$ training samples with which the regression model is to be built, where $x_{i} \in \Re^{d}$ and $y_{i} \in \Re$ are the set of the input features and the target for the i-th training sample, respectively. The SVR algorithm seeks to find a function $f(x)$ which fits all the training data with a deviation of at most $\varepsilon$ while being as flat as possible [44]. Without loss of generality, $f$ can be represented as a linear function as shown in Equation (1) where $\langle\ldots\rangle$ denotes the dot product in $\Re^{d}$.

$$
f(x)=\langle w, x\rangle+b w \in \mathbb{R}^{d}, b \in \mathbb{R}
$$

In order to make $f(x)$ flat, $w$ needs to be as small as possible. $w$ can be made small by minimizing its Euclidean norm $\|w\|^{2}=\langle w, w\rangle$. The corresponding convex optimization problem can be stated as shown in Equation (2) [45].

$$
\begin{array}{r}
\text { minimize } \frac{\|w\|^{2}}{2} \\
\text { subject to }\left\{\begin{array}{l}
y_{i}-\langle w, x\rangle-b \leq \varepsilon \\
\langle w, x\rangle+b-y_{i} \leq \varepsilon
\end{array}\right.
\end{array}
$$

Since Equation (2) may be infeasible, slack variables $\xi_{i}$ and $\xi_{i}^{*}$ are introduced to the optimization problem, yielding Equation (3).

$$
\begin{gathered}
\text { minimize } \frac{\|w\|^{2}}{2}+C \sum_{i=1}^{n}\left(\xi_{i}+\xi_{i}{ }^{*}\right) \\
\text { subject to }\left\{\begin{array}{c}
y_{i}-\langle w, x\rangle-b \leq \varepsilon+\xi_{i} \\
\langle w, x\rangle+b-y_{i} \leq \varepsilon+\xi_{i}{ }^{*} \\
\xi_{i}, \xi_{i}{ }^{*} \geq 0
\end{array}\right.
\end{gathered}
$$

The regularization constant $C$ controls the trade-off between generalization ability and accuracy on the training set [46]. Equation (3) can be solved more conveniently in its dual 
form by constructing a Lagrange function from the constraints and objective function, and introducing dual variables [44]. The solution to the dual problem is given in Equation (4):

$$
f(x)=\sum_{i=1}^{n}\left(\alpha_{i}+\alpha_{i}^{*}\right) \phi\left\langle x_{i}, x\right\rangle+b
$$

where $\alpha_{i}$ and $\alpha_{i}^{*}$ are Lagrange multipliers. $\varphi$ is the kernel function that allows the input features to be mapped to higher dimensional feature space. This mapping improves the accuracy and robustness of SVR [47]. In this work, the kernel function that performs better is the Gaussian kernel function and is defined in Equation (5).

$$
\phi\left\langle x_{i}, x\right\rangle=\exp \left(-\frac{\left\|x-x_{i}\right\|}{\sigma}\right)
$$

where $\sigma$ stands for the kernel option. Since the performance of SVR depends on the choice of hyper-parameters which include the regularization factor $(C)$, epsilon $(\varepsilon)$, and kernel option $(\sigma)$, genetic algorithm is hybridized with SVR for optimal selection of these parameters.

\subsection{Description of Genetic Algorithm}

Genetic algorithm (GA) is a population-based optimization algorithm inspired by evolution and natural selection, which is capable of solving complex search problems [48]. In GA, potential solutions to a problem are encoded as a chromosome, which is made up of a number of genes. At the start of GA, a population of chromosomes is randomly generated. The fitness level of each chromosome is determined by means of a fitness/cost function. High-quality chromosomes have a greater chance of being selected for reproduction than low-quality chromosomes. During reproduction (crossover), portions of two or more existing chromosomes are combined together to generate one or more offspring. Some chromosomes may undergo mutation, during which small random changes are introduced in a chromosome to prevent it from being stuck in a local optimum [49]. GA goes through several iterations (generations) of reproduction, crossover, and mutation until a stopping condition is met [45].

\subsection{Acquisition of Experimental Data and Computational Hybridization of the Proposed Models}

This section discusses the computational method adopted for hybridization of the two algorithms. The acquisition and description of the dataset used for modelling and simulation are also presented.

\subsubsection{Experimental Description and Data Acquisition}

Natural pozzolan (NP) was obtained from Imerys Minerals Arabia, Rabigh, Kingdom of Saudi Arabia and the limestone powder waste (LSPW) was collected from the local tile manufacturing plants. Subsequently, it was oven-dried at $105 \pm 5{ }^{\circ} \mathrm{C}$ for $24 \mathrm{~h}$ to remove the moisture. The LSPW was sieved through a $200 \mu \mathrm{m}$ sieve to remove stones and debris. The alkaline activator used in this study is a combination of commercially available aqueous sodium silicate (SS) with its initial silica modulus $\left(\mathrm{Ms}=\mathrm{SiO}_{2} / \mathrm{Na}_{2} \mathrm{O}\right)$ of 3.3 and $\mathrm{nM} \mathrm{NaOH}_{(\mathrm{aq})}(\mathrm{NH})$ where $\mathrm{n}$ is the value of the molarity $(4,6,8,10,12$, and 14). The percentage composition of the $\mathrm{Na}_{2} \mathrm{SiO}_{3(\mathrm{aq})}$ are as follows: $\mathrm{H}_{2} \mathrm{O}: 62.11 \%, \mathrm{SiO}_{2}: 29.13 \%$, and $\mathrm{Na}_{2} \mathrm{O}: 8.76 \%$. Desert sand [50] was used as fine aggregate (FA). The fineness modulus of FA was 1.82 and the specific gravity in saturated surface dry (SSD) condition was 2.63 and the water absorption was $0.5 \%$. The mixture proportions of AAMT were designed with the LSPW content of $0 \%, 20 \%, 40 \%, 60 \%, 80 \%$, and $100 \%$ and natural pozzolan contents of $100 \%, 80 \%, 60 \%, 40 \%, 20 \%$, and $0 \%$, respectively. The samples were designated as $\mathrm{AANL}_{\mathrm{x}}$ (alkali-activated NP/LSPW mortar), where $x$ is the $\frac{L}{L+N}$ ratios. A total of six AANL (where $x=0,0.2,0.4,0.6,0.8$ and 1 ) mixtures were prepared. The fine aggregate to the binder (FA/B) ratio ranged from 1.4 to 2.2 at an interval of 0.2 . The $\mathrm{Na}_{2} \mathrm{SiO}_{3(\mathrm{aq})} / \mathrm{NaOH}_{\mathrm{aq}}$ 
$(\mathrm{NS} / \mathrm{NH})$ ratio ranges from 0 to 1.5 and alkaline activator to binder ratio of $0.45,0.5$ and 0.55 were used. A free water to precursor (pozzolanic material) ratio of 0.1 was used in all the mixtures. The required quantities of constituent materials were measured and mixed in batches in the $5.0 \mathrm{~L}$ capacity Hobart planetary bench mixer (Hobart GmbH, Offenburg, Germany). The mixing of the materials was done in two stages. In the initial stage, the NP and LSPW powder and sand were mixed in a dry condition for $3 \mathrm{~min}$. In the second stage, the alkaline solution $\left(\mathrm{NaOH}_{(\mathrm{aq})}+\mathrm{Na}_{2} \mathrm{SiO}_{3(\mathrm{aq})}\right)$ and water were added for the wet mixing stage which involves low speed mixing for $2 \mathrm{~min}$ and another $4 \mathrm{~min}$ for fast or high speed mixing until a homogeneous mixture was achieved, the total mixing time was about 9 to 10 min to ensure the homogeneity of the mix. Thereafter, the mortar was placed in oil-smeared steel molds measuring $50 \times 50 \times 50 \mathrm{~mm}$ in two layers and each layer was vibrated on the vibrating table for $30 \mathrm{~s}$ to remove any entrapped air from the mixture. Then the surface was carefully smoothened with a trowel to have a smooth finish. After placement, consolidation, and finishing of the mortar, the specimens were covered with a plastic sheet to prevent moisture loss and kept in the laboratory at $20 \pm 5^{\circ} \mathrm{C}$ for $24 \mathrm{~h}$. After $24 \mathrm{~h}$ of casting, the cubes were de-molded and placed in zip plastic bags to avoid evaporation of moisture. The specimens were then subjected to temperature curing in an oven maintained at the room temperature $\left(20 \pm 5^{\circ} \mathrm{C}\right)$ and various curing temperature of $45,60,75$, and $90{ }^{\circ} \mathrm{C}$ for $24 \mathrm{~h}$. After that, the specimens were cured under a normal room temperature condition of $20 \pm 5{ }^{\circ} \mathrm{C}$ until the age of testing $(1,3,7,14$, and 28 days). The CS of the AANL mortar was determined in accordance with ASTM C 39 [51] on $50 \times 50 \times 50 \mathrm{~mm}$ cube specimens using a digital compression testing machine. The CS of the specimens was determined after 1 , $3,7,14$, and 28 days of curing. Three specimens were tested at each age and the average compressive strength values were recorded for use in the models. Table 1 summarizes the quantities of materials and the compressive strength of 390 alkali-activated specimens.

Table 1. Mixture proportions of alkali-activated natural pozzolan/limestone powder mortar specimens.

\begin{tabular}{|c|c|c|c|c|c|c|c|c|c|c|c|}
\hline Mix & $\begin{array}{l}X \\
-\end{array}$ & $\underset{\mathrm{mol} / \mathrm{dm}^{3}}{\mathrm{M}}$ & $\begin{array}{c}\mathrm{T} \\
\left({ }^{\circ} \mathrm{C}\right)\end{array}$ & $\begin{array}{c}\text { NS/NH } \\
-\end{array}$ & $\begin{array}{c}\text { FA/B } \\
-\end{array}$ & $\begin{array}{c}\mathrm{AK} / \mathrm{B} \\
-\end{array}$ & $\begin{array}{c}\text { CS-1 } \\
\text { (MPa) }\end{array}$ & $\begin{array}{l}\text { CS-3 } \\
\text { (MPa) }\end{array}$ & $\begin{array}{l}\text { CS-7 } \\
\text { (MPa) }\end{array}$ & $\begin{array}{l}\text { CS-14 } \\
\text { (MPa) }\end{array}$ & $\begin{array}{l}\text { CS-28 } \\
\text { (MPa) }\end{array}$ \\
\hline M1 & 0 & 10 & 75 & 1 & 2 & 0.5 & 4.4 & 4.9 & 5.2 & 7.4 & 8.9 \\
\hline M2 & 0.2 & 10 & 75 & 1 & 2 & 0.5 & 18.6 & 18.7 & 21.9 & 22.4 & 22.6 \\
\hline M3 & 0.4 & 10 & 75 & 1 & 2 & 0.5 & 20.7 & 23.9 & 24.3 & 24.5 & 25.0 \\
\hline M4 & 0.6 & 10 & 75 & 1 & 2 & 0.5 & 20.9 & 24.0 & 25.2 & 25.3 & 27.0 \\
\hline M5 & 0.8 & 10 & 75 & 1 & 2 & 0.5 & 12.9 & 14.0 & 14.5 & 15.3 & 15.7 \\
\hline M6 & 1 & 10 & 75 & 1 & 2 & 0.5 & 5.3 & 5.6 & 5.8 & 6.0 & 6.3 \\
\hline M7 & 0.6 & 4 & 75 & 1 & 2 & 0.5 & 4.3 & 4.4 & 4.8 & 5.3 & 6.0 \\
\hline M8 & 0.6 & 6 & 75 & 1 & 2 & 0.5 & 4.7 & 4.9 & 5.0 & 5.6 & 7.6 \\
\hline M9 & 0.6 & 8 & 75 & 1 & 2 & 0.5 & 7.9 & 8.4 & 9.0 & 9.8 & 11.6 \\
\hline M10 & 0.6 & 12 & 75 & 1 & 2 & 0.5 & 20.2 & 24.3 & 24.7 & 24.7 & 22.8 \\
\hline M11 & 0.6 & 14 & 75 & 1 & 2 & 0.5 & 21.6 & 23.6 & 24.7 & 24.0 & 22.7 \\
\hline M12 & 0.6 & 10 & 25 & 1 & 2 & 0.5 & 6.85 & 7.73 & 10.55 & 11.68 & 13.00 \\
\hline M13 & 0.6 & 10 & 45 & 1 & 2 & 0.5 & 10.68 & 12.47 & 12.76 & 13.25 & 14.13 \\
\hline M14 & 0.6 & 10 & 60 & 1 & 2 & 0.5 & 17.06 & 19.34 & 20.36 & 20.86 & 22.00 \\
\hline M15 & 0.6 & 10 & 90 & 1 & 2 & 0.5 & 23.35 & 24.13 & 24.37 & 24.84 & 25.92 \\
\hline M16 & 0.6 & 10 & 75 & 0 & 2 & 0.5 & 9.6 & 14.4 & 13.2 & 14.3 & 15.6 \\
\hline M17 & 0.6 & 10 & 75 & 0.5 & 2 & 0.5 & 15.4 & 18.3 & 18.9 & 19.1 & 18.9 \\
\hline M18 & 0.6 & 10 & 75 & 0.75 & 2 & 0.5 & 17.1 & 19.1 & 19.0 & 19.5 & 20.4 \\
\hline M19 & 0.6 & 10 & 75 & 1.25 & 2 & 0.5 & 18.3 & 18.9 & 18.8 & 15.3 & 16.2 \\
\hline M20 & 0.6 & 10 & 75 & 1.5 & 2 & 0.5 & 10.9 & 12.3 & 13.4 & 10.5 & 10.9 \\
\hline M21 & 0.6 & 10 & 75 & 1 & 1.4 & 0.5 & 15.4 & 18.3 & 20.1 & 22 & 23.5 \\
\hline M22 & 0.6 & 10 & 75 & 1 & 1.6 & 0.5 & 17.6 & 20.6 & 22.4 & 23.3 & 24.3 \\
\hline M23 & 0.6 & 10 & 75 & 1 & 1.8 & 0.5 & 18.2 & 21.2 & 23.6 & 24.2 & 25 \\
\hline M24 & 0.6 & 10 & 75 & 1 & 2.2 & 0.5 & 19.5 & 21.3 & 22.8 & 23.4 & 24.4 \\
\hline M25 & 0.6 & 10 & 75 & 1 & 2 & 0.45 & 20.3 & 22.2 & 23.7 & 25.0 & 23.7 \\
\hline M26 & 0.6 & 10 & 75 & 1 & 2 & 0.55 & 21.5 & 23.6 & 22.8 & 23.1 & 22.5 \\
\hline
\end{tabular}

Statistical analysis was carried out on the dataset presented in Table 1 and the outcomes of the analysis are presented in Table 2. The mean and the range presented in the Table 2 give significant insights to the overall content of the dataset while the consistencies in the dataset from one measurement to another is contained in the acceptable standard deviation. The correlation coefficient (CC) shows the degree of a linear relationship between each of the descriptors and the targets. From these coefficients, the inadequacy of linear models to holistically capture the relationship between the descriptors and the targets can be 
inferred. Hence, the need for nonlinear modelling, such as the proposed hybrid GA-SVR, becomes paramount.

Table 2. Outcomes of the statistical analysis performed on the dataset used for modelling and simulation.

\begin{tabular}{ccccccccc}
\hline Parameter & Mean & Range & $\begin{array}{c}\text { Standard } \\
\text { Deviation }\end{array}$ & $\begin{array}{c}\text { CC-1 } \\
\mathbf{( M P a )}\end{array}$ & $\begin{array}{c}\text { CC-3 } \\
\mathbf{( M P a})\end{array}$ & $\begin{array}{c}\text { CC-7 } \\
\mathbf{( M P a})\end{array}$ & $\begin{array}{c}\text { CC-14 } \\
\mathbf{( M P a})\end{array}$ & $\begin{array}{c}\text { CC-28 } \\
\mathbf{( M P a})\end{array}$ \\
\hline $\mathrm{X}$ & 0.577 & 1 & 0.173 & -0.026 & -0.007 & -0.035 & -0.073 & -0.095 \\
$\mathrm{M}\left(\mathrm{mol} / \mathrm{dm}^{3}\right)$ & 9.769 & 10 & 1.728 & 0.578 & 0.605 & 0.609 & 0.589 & 0.545 \\
$\mathrm{~T}\left({ }^{\circ} \mathrm{C}\right)$ & 71.923 & 65 & 12.006 & 0.329 & 0.308 & 0.255 & 0.236 & 0.226 \\
$\mathrm{NS} / \mathrm{NH}$ & 0.962 & 1.5 & 0.252 & 0.083 & -0.021 & 0.032 & -0.042 & -0.055 \\
$\mathrm{FA} / \mathrm{B}$ & 1.962 & 0.8 & 0.150 & -0.055 & -0.102 & -0.144 & -0.189 & -0.225 \\
$\mathrm{AK} / \mathrm{B}$ & 0.500 & 0.1 & 0.014 & 0.027 & 0.029 & -0.016 & -0.039 & -0.024 \\
$\mathrm{CS}-1(\mathrm{MPa})$ & 14.737 & 19.05 & 6.187 & & & & & \\
$\mathrm{CS}-3(\mathrm{MPa})$ & 16.556 & 19.9 & 6.871 & & & & & \\
$\mathrm{CS}-7(\mathrm{MPa})$ & 17.376 & 20.4 & 7.053 & & & & & \\
CS-14(MPa) & 17.714 & 20 & 7.004 & & & & & \\
CS-28 $(\mathrm{MPa})$ & 18.328 & 21 & 6.655 & & & & & \\
\hline
\end{tabular}

\subsubsection{Computational Hybridization of Genetic Algorithm and Support Vector Regression}

Due to the fact that the performance of SVR is highly dependent on the set of SVR parameters used, it is important to fine-tune the parameters of SVR in order to obtain a good prediction. All the modelling and simulation were conducted within the MATLAB (2019 MathWorks, Natick, MA, USA) computing environment. Before the commencement of modelling, the dataset was divided into training, testing, and validation in the ratio 6:2:2 after randomization. Randomization of data is necessary to ensure an even distribution of data-points and to promote efficient computation. Therefore, 16 data-points were used for training the model, five data-points were used for tuning the hyper-parameters, while the remaining five data-points were used for validating the robustness of the developed hybrid model. The procedures for hybridization of SVR with GA are itemized below:

Step I: Chromosome representation and population initialization: Each chromosome is real-coded and made up of three genes representing regularization factor, epsilon, and kernel option for the selected kernel function. The search space which represents the range of valid values for each of the parameters is defined as 1-1000 for regularization factor, $0.1-1$ for epsilon, and 0.001 to 1 for kernel option. These wide ranges of search space enhance the possibility of attaining the optimality. The initial population of chromosomes was formed by randomly assigning values for each parameter within its lower and upper bounds.

Step II: Fitness value computation: In order to compute the fitness value for each of the chromosome, the kernel function was selected from a pool of functions which include Gaussian, polynomial and sigmoid among others while the hyper-parameter that defines the hyper-plane was set at $10^{-7}$. Thereafter, the values of other SVR parameters (which include regularization constant, epsilon and kernel option) are encoded in the chromosome. The set of parameters as well as the training set of data were used to train SVR algorithm. The generalization capability and robustness of the SVR prediction model is measured by implementing the model to estimate the compressive strength of data samples contained in the validation set and computing the root mean square error (RMSE) between the estimated compressive strength and the empirically measured comprehensive strength. Therefore, the fitness value of a chromosome is the RMSE of the corresponding SVR model on the validation set of data.

Step III: Selection for reproduction: Based on the principle of survival of the fittest, the chromosomes having higher quality (i.e., lower RMSE) have a greater chance of being selected for reproduction. Tournament selection was utilized in the present hybrid GA-SVR model. In tournament selection, a few chromosomes were randomly chosen from the entire population and the winner of the tournament, which is the fittest of the chosen chromosomes, was used for crossover. The selection probability was set at 0.8 .

Step IV: Crossover: The crossover operator combines portions of two parents to form two offspring. Subsequences and portions of both parents are swapped among the children with a crossover probability of 0.65 . 
Step IV: Mutation: With a mutation probability of 0.009 , the value at a randomly chosen position in a chromosome was altered.

Step V: Stopping criteria: Step I to Step IV was repeated until the best fitness value does not improve over 60 consecutive generations. Figure 1 presents the computational flow chat of the hybridization.

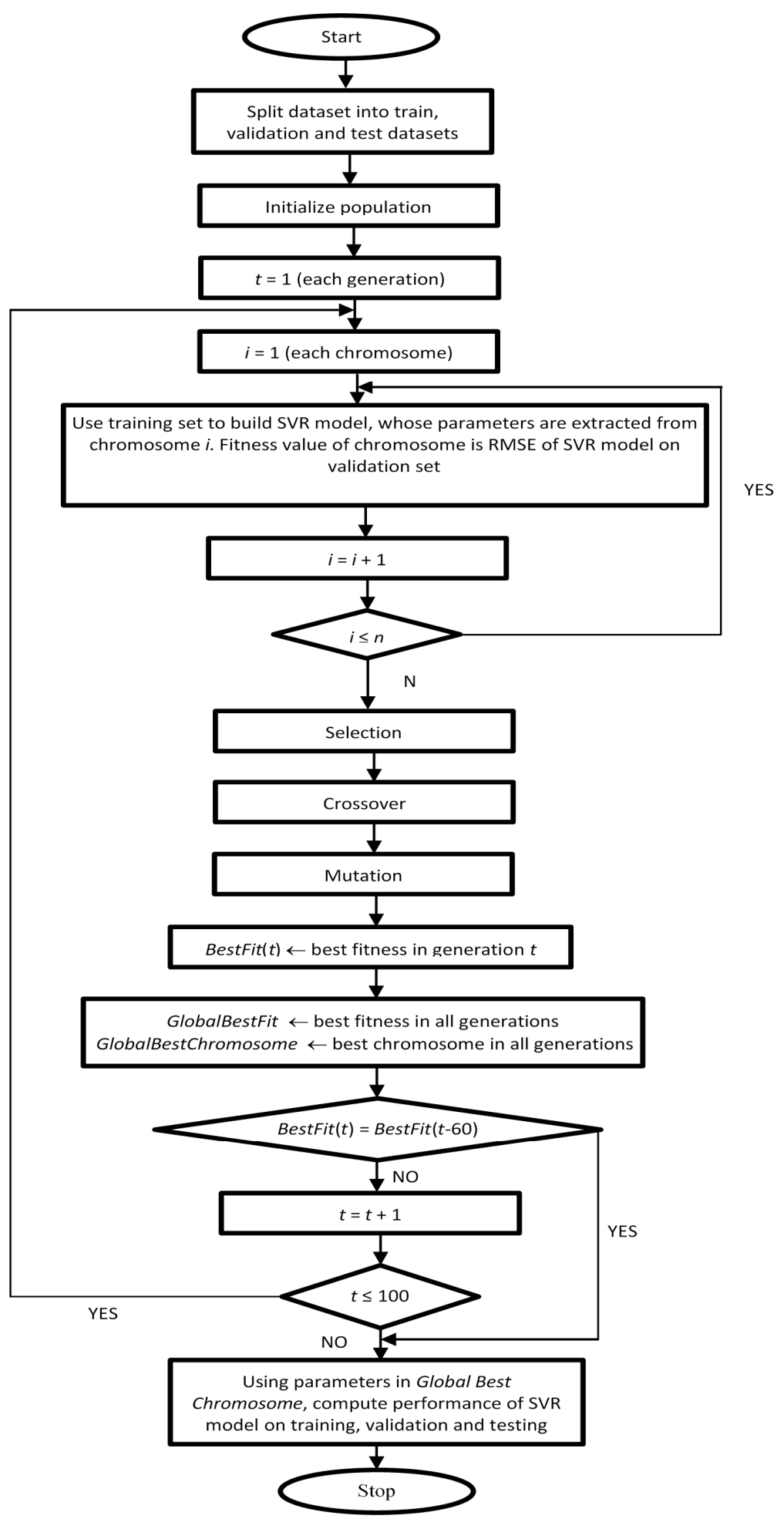

Figure 1. Computational Flow chart of GA-SVR for prediction of compressive strength. 


\section{Results and Discussion}

This section presents and discusses the results of the modelling, simulation, and optimization. The outcomes of the developed models are compared with the experimental values while the developed models are implemented for modelling the behavior of the compressive strength under various conditions.

\subsection{Early Age Compressive Strength Using the Developed Hybrid Models}

The results of early age compressive strength as estimated using the developed hybrid GA-SVR-CS1, GA-SVR-CS3, GA-SVR-CS7, and GA-SVR-CS14 model for one-, three-, seven-, and 14-days, respectively, are presented in this section. The convergence of the models at various numbers of initial populations is also discussed. The effectiveness of each of the models in obtaining maximum desired compressive strength is also discussed.

3.1.1. Optimization of SVR Hyper-Parameters for the Early and 14-Day Compressive Strength Models

Since the hyper-parameters of SVR algorithm are of high significance to the performance of the model, these parameters were optimized using GA. The convergence of the hybrid GA-SVR-CS1 and GA-SVR-CS3 models is presented in Figure 2.

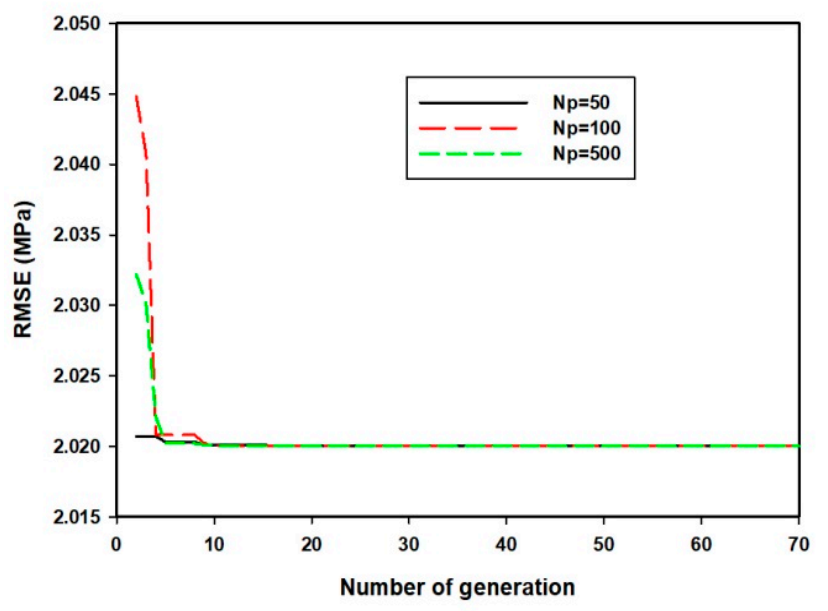

(a)

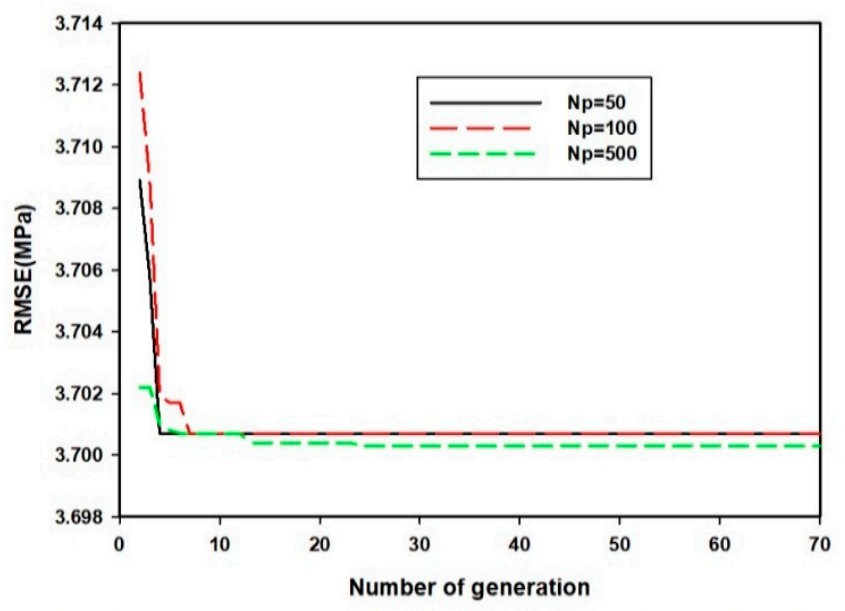

(b)

Figure 2. (a) Convergence of hybrid GA-SVR-CS1 to the number of generations at different population size (b) Convergence of hybrid GA-SVR-CS3 to the number of generations at different population size.

Figure 2a shows the convergence of GA-SVR-CS1 at different number of initial population while Figure $2 b$ presents the convergence of GA-SVR-CS3 model at three different numbers of initial populations. Both graphs in Figure 2 strongly indicate the robustness of the models as they converge to the same point, despite the large size of the population. Similar convergence is obtained for GA-SVR-CS7 and GA-SVR-CS14 models, developed for estimating seven- and fourteen-days compressive strength, respectively. Only the convergence of GA-SVR-CS1 and GA-SVR-CS3 models is presented so as to prevent repetition. Table 3 presents the obtained hyper-parameters for each of the developed early-age compressive strength models. 
Table 3. Optimized hyper-parameters of the early-age strength compressive strength models.

\begin{tabular}{cccccc}
\hline Model & $\begin{array}{c}\text { Regularization } \\
\text { Factor }\end{array}$ & Epsilon & $\begin{array}{c}\text { Kernel } \\
\text { Option }\end{array}$ & $\begin{array}{c}\text { Hyper-Parameter } \\
\text { Lambda }\end{array}$ & $\begin{array}{c}\text { Kernel } \\
\text { Function }\end{array}$ \\
\hline $\begin{array}{c}\text { Hybrid } \\
\text { GA-SVR-CS1 } \\
\text { Hybrid }\end{array}$ & 418.5247 & 0.7126 & 0.3201 & 0.1 & Gaussian \\
$\begin{array}{c}\text { GA-SVR-CS3 } \\
\text { Hybrid }\end{array}$ & 417.1485 & 0.002 & 0.4056 & 0.1 & Gaussian \\
$\begin{array}{c}\text { GA-SVR-CS7 } \\
\text { Hybrid }\end{array}$ & 36.7688 & 0.0539 & 2.0000 & 0.1 & Gaussian \\
GA-SVR-CS14 & 457.0419 & 0.002 & 0.2433 & 0.1 & Gaussian \\
\hline
\end{tabular}

3.1.2. Performance of the Developed Early-Age Compressive Strength Models at Each Developmental Stage

The performance of each of the developed models for estimating the strength of AALNM is assessed using correlation coefficient (CC) between the estimated and experimentally measured values, root mean square error (RMSE), and mean absolute error (MAE) for training, testing, and validating the set of data. The values of each of the parameters at each of the developmental stages of the model are presented in Table 4. The validation stage is the most vital stage by which the accuracy as well the generalization and predictive strength of the models can be assessed since the models are subjected to data that are not involved in both training and testing stages. In the training phase, support vectors are acquired while these support vectors are altered and perfected to give excellent estimation using the testing set of data for parameters tuning. The developed GA-SVR-CS1 model performs better at validation stage than training and testing stage with the performance improvement of $17.48 \%$ and $47.52 \%$, respectively, using RMSE as a performance measuring parameter. However, a comparison of validation stage with training and testing stage on the basis of MAE shows that the developed GA-SVR-CS1 model performs better during the validation than training and testing stage with performance enhancement of $8.15 \%$ and $75.04 \%$, respectively. On the basis of CC, the performance at the validation stage is better than that of the training phase while the best performance is obtained during the testing phase. Table 4 presents the value of each of the performance measuring parameters for each of the early-age compressive strength models. In the case of developed hybrid GASVR-CS3 model for estimating three-days compressive strength, the model performs better during the validation stage compared with the training stage while the best performance was recorded during the initial acquisition of support vectors using the three performance measuring parameters as a yardstick for comparison. The testing phase of GA-SVR-CS7 model shows the best performance metrics while in the case of GA-SVR-CS14 model, the training phase of the model demonstrates the best performance.

Table 4. Reliability measurement for the early-age and 14-day compressive strength models.

\begin{tabular}{cccc}
\hline Model & Training & Testing & Validation \\
\hline Hybrid GA-SVR-CS1 & & & \\
CC & 0.9315 & 0.9779 & 0.9664 \\
RMSE & 2.1655 & 2.7192 & 1.8432 \\
MAE & 1.5296 & 2.4756 & 0.9084 \\
Hybrid GA-SVR-CS3 & & & 1.4896 \\
CC & 0.9952 & 0.6755 & 1.2969 \\
RMSE & 1.1651 & 3.7007 & 0.6557 \\
MAE & 0.9163 & 2.5532 & 5.0503 \\
CC & & & 4.9916 \\
RMSE & 0.7039 & 0.8284 & 0.934 \\
MAE & 5.2789 & 4.6159 & 3.0103 \\
CC & 3.108 & 4.0925 & 2.7793 \\
RMSE & & & 0.9541 \\
MAE & 0.9768 & 2.7784 & 2.3586 \\
\hline
\end{tabular}


3.1.3. Comparison between the Experimentally-Measured Early and 14-Day Compressive Strength and the Outcomes of the Developed Hybrid Models

A comparison of the predicted early-age compressive strength and the measured values for AALNM mixtures is presented in Figure 3 for the developed GA-SVR-CS1 and GA-SVR-CS3 models. The predicted compressive strength is very close to the experimental values, as shown in Figure 3. Similar closeness is obtained for the other two early-age compressive strength models (GA-SVR-CS7 and GA-SVR-CS14). The actual values of the estimated compressive strength for each of the developed early-age compressive strength models are provided in Appendix A.

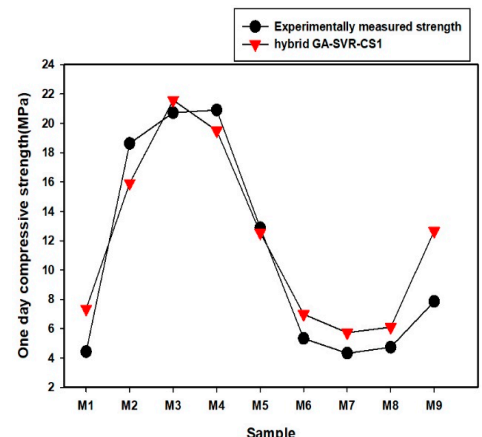

(a)

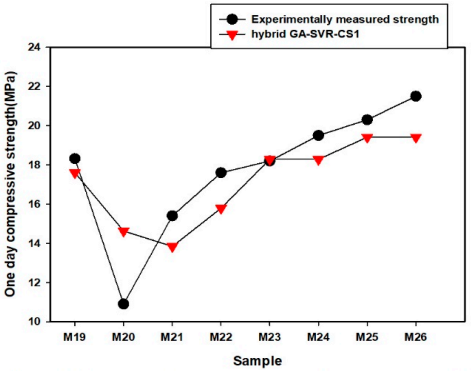

(c)

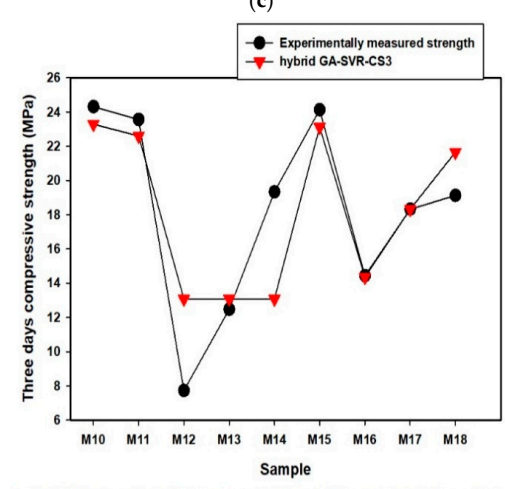

(e)

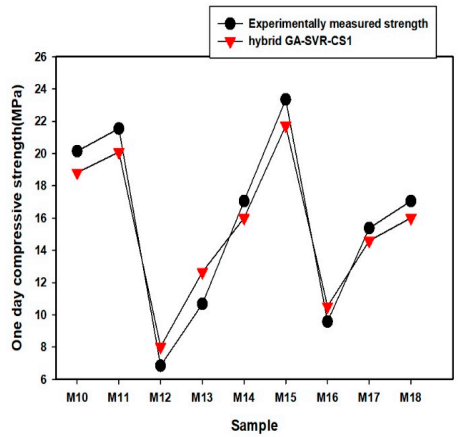

(b)

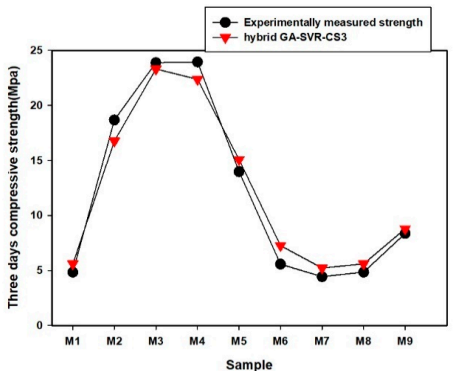

(d)

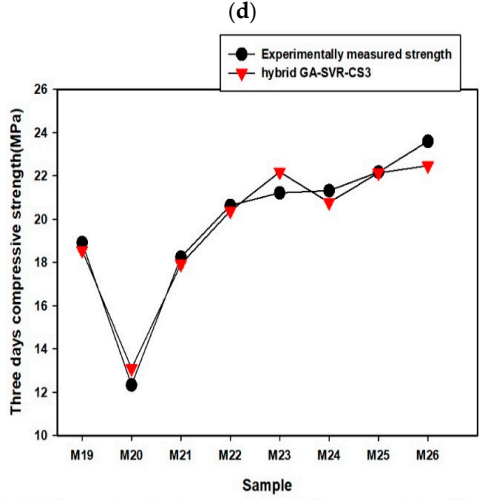

(f)

Figure 3. (a) Comparison between experimentally measured one-day compressive and results of the developed hybrid GA-SVR-CS1 for samples M1-M9 (b) Comparison between experimentally measured one-day compressive and results of the developed hybrid GA-SVR-CS1 for samples M10M18 (c) Comparison between experimentally measured one-day compressive and results of the developed hybrid GA-SVR-CS1 for samples M19-M26 (d) Comparison between experimentally measured three-day compressive and results of the developed hybrid GA-SVR-CS1 for samples M1-M9 (e) Comparison between experimentally measured three-day compressive and results of the developed hybrid GA-SVR-CS1 for samples M10-M18 (f) Comparison between experimentally measured three-day compressive and results of the developed hybrid GA-SVR-CS1 for samples M19-M26. 
3.2. Modelling the Influence of Constituents of AALNM on the Early-Age and 14-Day Compressive Strength Using the Developed Hybrid Models

The developed early-age compressive strength models, specifically GA-SVR-CS1 and GA-SVR-CS3, are implemented for investigating the influence of binary binder ratio and the fine aggregate to binder ratio on the early-age compressive strength. This application becomes necessary since the proposed early-age compressive strength models have been trained, tested, and validated with the experimental data and the performance measuring parameters recorded are excellent. Figure 4a shows the dependence of one-day compressive strength on the binary binder ratio (that is, the ratio of limestone powder to natural pozzolan represented as $\mathrm{x}$ ) at various molarity (represented by $\mathrm{M}$ ) of sodium hydroxide while keeping the curing temperature $(\mathrm{T})$, sodium silicate to sodium hydroxide (NS/NH) ratio, fine aggregate to binder ratio (FA/B), and alkaline to binder ratio (AK/B) at $75{ }^{\circ} \mathrm{C}, 1$, 2 , and 0.5 , respectively. It was noted that the one-day compressive strength of AALNM mixture increases with binary binder ratio (except when the molarity of sodium hydroxide is 6), attains maximum strength, and begins to decrease. The one-day compressive strength attains maximum value when the molarity of sodium hydroxide is 10 and the ratio of binary binder ratio is 0.45 [52]. It should be noted here that the developed GA-SVR-CS1 model was only fed with input descriptors while the developed model utilizes its acquired support vectors during training phase to predict the behavior of AALNM mixture under the selected conditions. Figure $4 \mathrm{~b}$ presents the influence of fine aggregate to binder ratio on one-day compressive strength of AALNM system at various sodium silicate to sodium hydroxide ratios, keeping binary binder ratio at its optimum value of 0.45 .

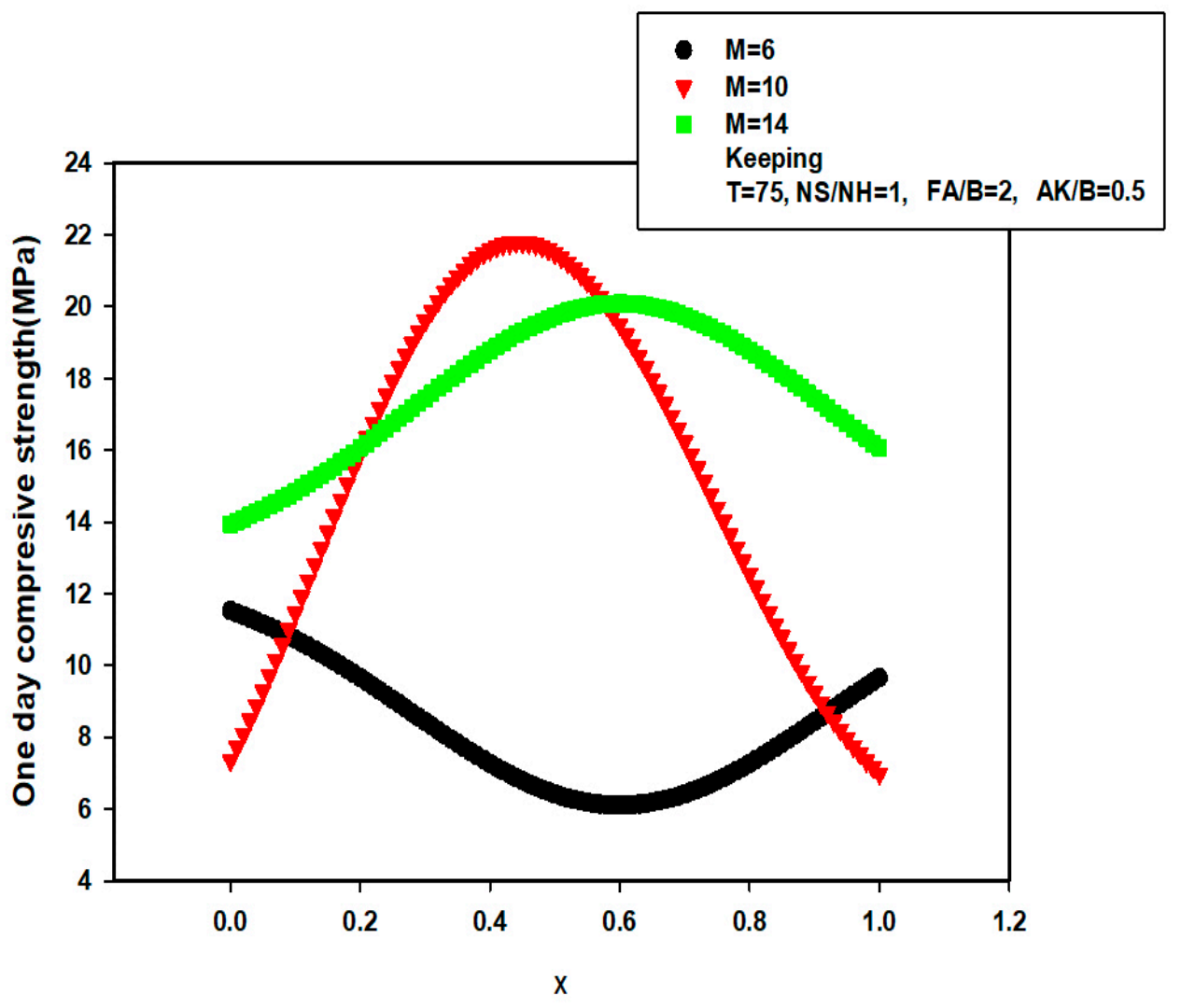

(a)

Figure 4. Cont. 


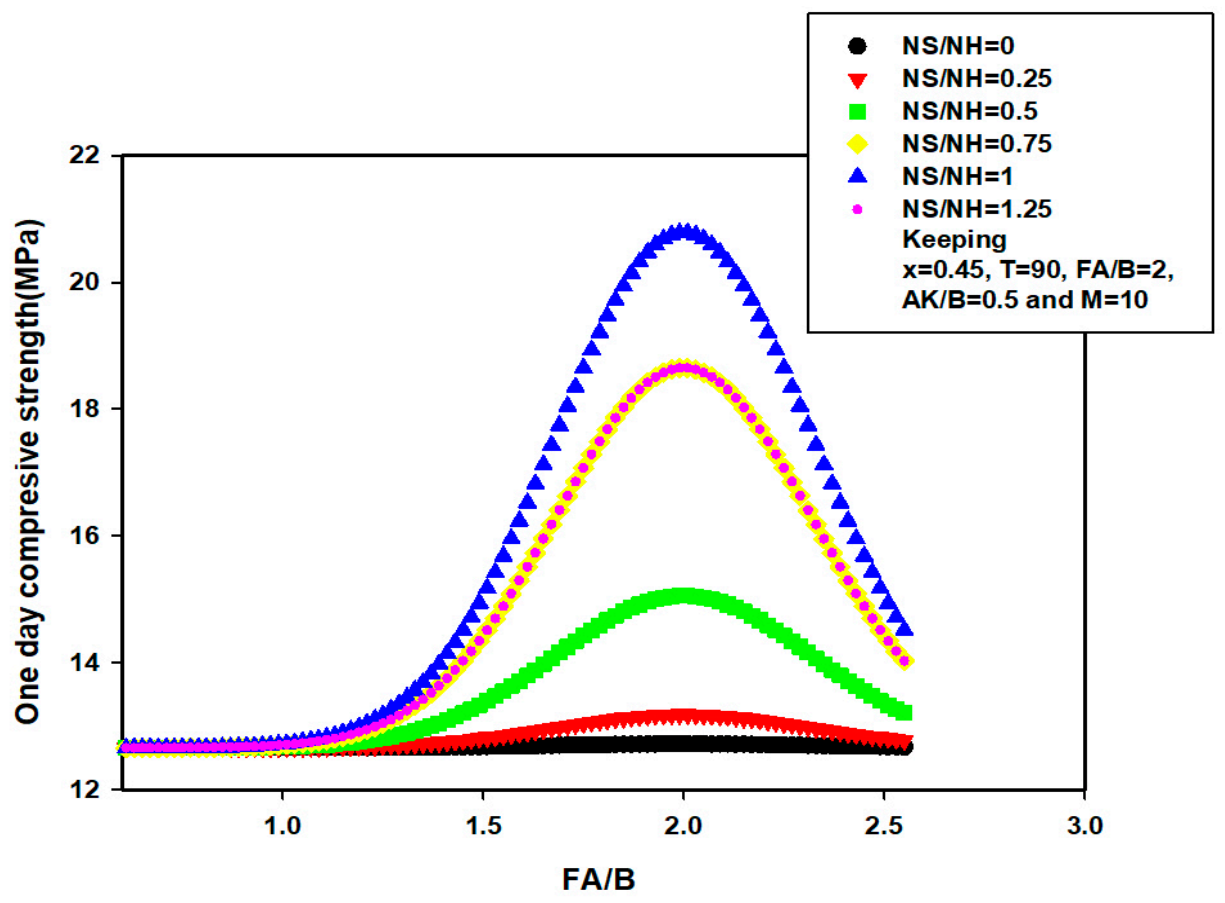

(b)

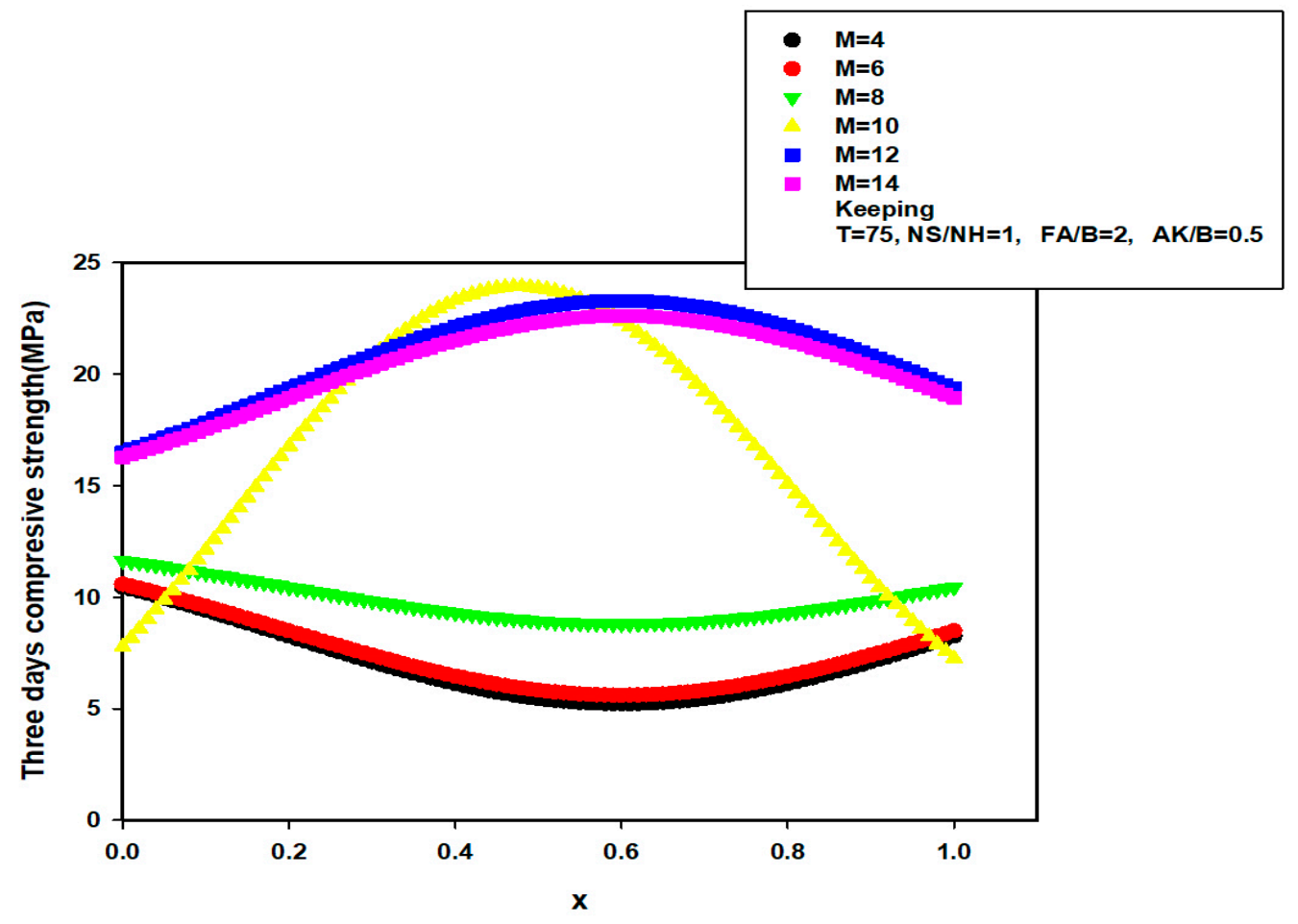

(c)

Figure 4. Cont. 


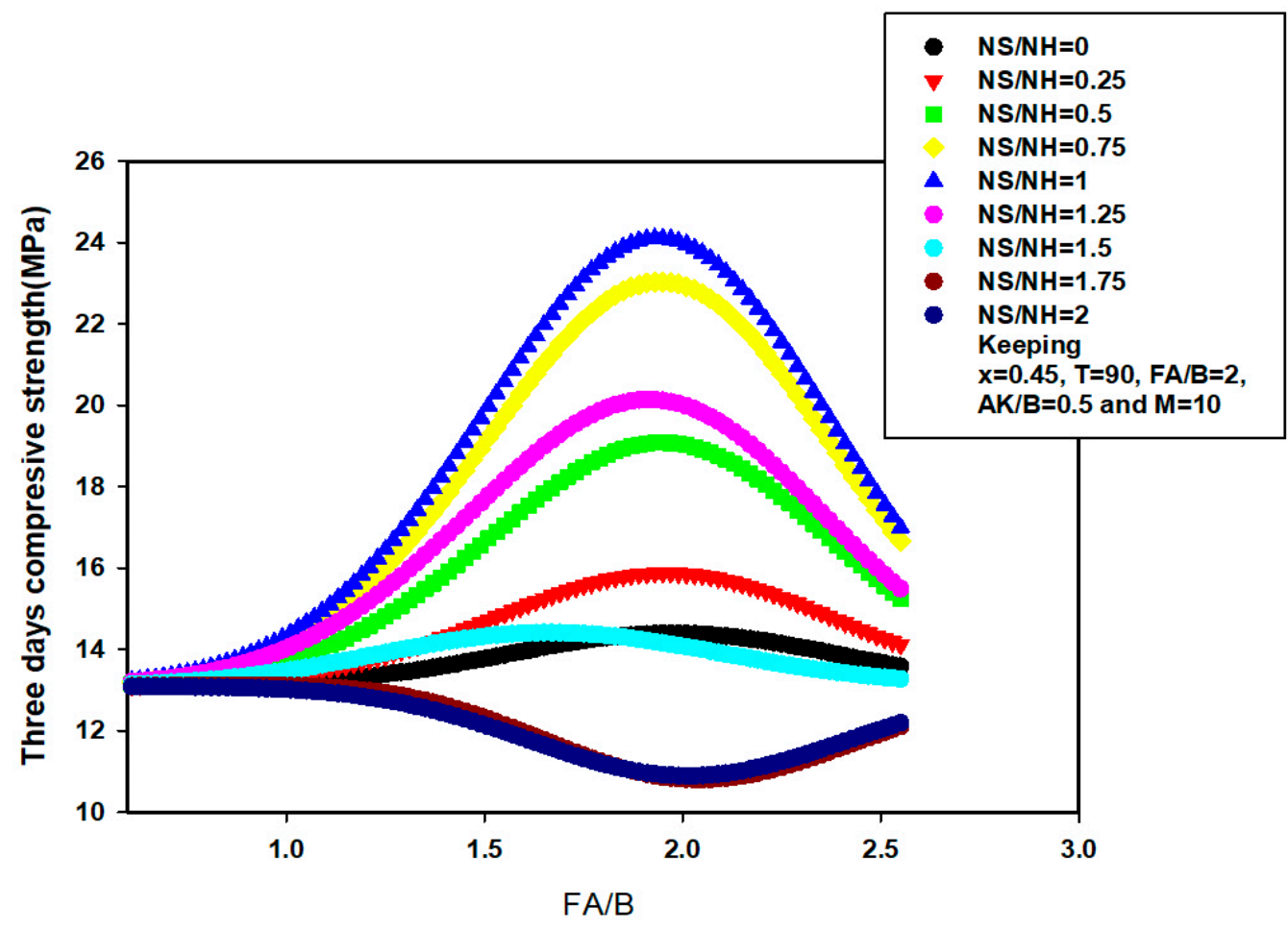

(d)

Figure 4. (a) Dependence of one day compressive strength of AANLM at various molarity on the ratio of LSP/NP+LSPW using the developed hybrid GA-SVR-CS1 (b) Dependence of one day compressive strength of AANLM at various NS/NH on the ratio of FA/B using the developed hybrid GA-SVR-CS1 (c) Dependence of three day compressive strength of AANLM at various molarity on the ratio of LSP/NP+LSPW using the developed hybrid GA-SVR-CS3 model (d) Dependence of three day compressive strength of AANLM at various NS/NH ratio on the ratio of FA/B using the developed hybrid GA-SVR-CS3 model.

The data in Figure $4 \mathrm{~b}$ indicates that the maximum one-day strength can only be achieved when FA/B is 2 while NS/NH is kept at 1 . The results of similar investigation are presented in Figure 4c, d for three-days compressive strength using the developed GASVR-CS3 model. Figure 4c presents the dependence of three-days compressive strength on the binary binder ratio at different molarity of sodium hydroxide while setting the curing temperature $(\mathrm{T})$, sodium silicate to sodium hydroxide (NS/NH) ratio, fine aggregate to binder ratio (FA/B) and alkaline to binder ratio (AK/B) at $75^{\circ} \mathrm{C}, 1,2$, and 0.5 , respectively. The behavior of AALNM mixture is parabolic in nature while the strength at molarity of 4 and 6 show minimum points correspond to minimum possible compressive strength. The results of modeling and simulation as presented in Figure $4 \mathrm{c}$ show that the maximum three-days strength possible could be obtained when the binary binder ratio is set at 0.45 while the molarity of sodium hydroxide is maintained at 10 . At this optimum binary binder ratio, the significance of FA/B on three-days compressive strength at various values of NS/NH ratio is investigated and the results are presented in Figure 4d. It was observed that after a maximum possible three-days strength at NS/NH ratio of 1 , further increase in NS/NH lowers the strength.

\subsection{Estimation of 28-Days Compressive Strength Using the Developed Hybrid GA-SVR-CS28 Model}

This research work also developed models that can effectively estimate the 28-days compressive strength for structural and construction purposes. In this case, five different models were developed with distinct features, capacities and estimation accuracy. The developed hybrid GA-SVR-CS28A model estimates the 28-days compressive strength 
of AALNM mixture using binary binder variation, sodium hydroxide molarity $(\mathrm{NH})$, curing temperature, sodium silicate to sodium hydroxide $(\mathrm{NS} / \mathrm{NH})$ ratio, alkaline to binder ratio $(\mathrm{AK} / \mathrm{B})$, and fine aggregate to binder (FA/BD) ratio as input descriptors to the model. Furthermore, the developed hybrid GA-SVR-CS28B and GA-SVR-CS28C models estimate the 28-day compressive strength using one-day and three-day compressive strength as input descriptor while the seven-days compressive strength serves as the descriptor to GA-SVR-CS28D model. Another developed hybrid GA-SVR-CS28E model predicts the 28-day strength using 14-day strength as descriptor. Each of these models have unique importance and significance. The developed hybrid GA-SVR-CS28B model allows engineers and practitioners to predict 28-day compressive strength using the results of one-day compressive strength so as to save precious time and other valuable resources. Since it saves time and preserves experimental precision, the model can be deployed for making quick and precise decision in building industries. Similar advantages are attached to other models, such as GA-SVR-CS28C, GA-SVR-CS28D, and GA-SVR-CS28E. The choice from these models can be decided on the basis of their accuracies and the urgency of the application. It is worth noting that mixtures M10, M11, M17, and M25 exhibited a slight reduction in compressive strength after 14-days. Mixtures M10, M11, M17, and M25 were all synthesized with high concentration of sodium hydroxide $\mathrm{NaOH}_{(\mathrm{aq})}$, at higher concentration of $\mathrm{NaOH}_{(\mathrm{aq})}$, the early-days compressive strength values are higher due to the rapid geopolymerization process caused by high dissolution rate of monomers in the binder. However, at later stage, excessive presence of $\mathrm{OH}^{-}$in high molar concentration of $\mathrm{NaOH}_{(\mathrm{aq})}$ could cause ionic congestion that might prevent the polymerization process. This could limit the formation of C-A-S-H in the formed gels leading to a reduction in the compressive strength as observed in mixtures M10, M11, M17, and M25 [52].

\subsubsection{Optimization of SVR Hyper-Parameters for the Developed GA-SVR-CS28 Model}

The hyper-parameters of each of the developed 28-days compressive strength models are optimized using GA. The optimum values of the hyper-parameters are presented in Table 5, while results showing the convergence of the optimization are presented in Figure 5a-e. As shown in Figure 5c, the developed model attained local minimum when fifty of the population were contained within the search space because the space is limited, while the exploration capacity of the model becomes inefficient. An increase in the number of probable solutions in the search space to one hundred strengthens the exploration capacity of the model and the optimum convergence was observed. Among the merits of the implemented GA is that it avoids local minimum convergence, especially when the initial population is varied.

Table 5. Optimized hyper-parameters of 28-days compressive strength models.

\begin{tabular}{cccccc}
\hline Model & $\begin{array}{c}\text { Regularization } \\
\text { Factor }\end{array}$ & Epsilon & $\begin{array}{c}\text { Kernel } \\
\text { Option }\end{array}$ & $\begin{array}{c}\text { Hyper-Parameter } \\
\text { Lambda }\end{array}$ & $\begin{array}{c}\text { Kernel } \\
\text { Function }\end{array}$ \\
\hline $\begin{array}{c}\text { Hybrid } \\
\text { GA-SVR-CS28A }\end{array}$ & 689.1925 & 0.002 & 0.6379 & 0.1 & Gaussian \\
$\begin{array}{c}\text { Hybrid } \\
\text { GA-SVR-CS28B }\end{array}$ & 15.124 & 0.5571 & 2 & 0.1 & Gaussian \\
$\begin{array}{c}\text { Hybrid } \\
\text { GA-SVR-CS28C }\end{array}$ & 7.7528 & 0.3432 & 2 & 0.1 & Gaussian \\
$\begin{array}{c}\text { Hybrid } \\
\text { GA-SVR-CS28D }\end{array}$ & 1.000 & 0.002 & 2 & 0.1 & Gaussian \\
Hybrid & 13.7523 & 0.002 & 2 & 0.1 & Gaussian \\
\hline GA-SVR-CS28E & & &
\end{tabular}




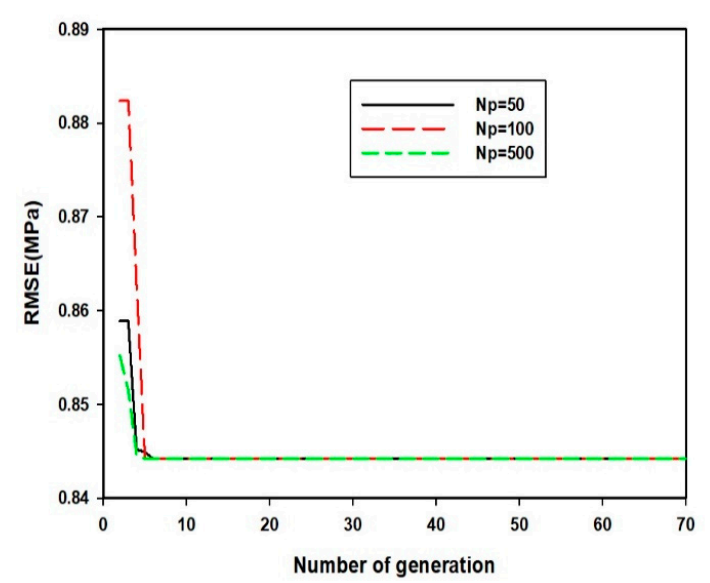

(a)

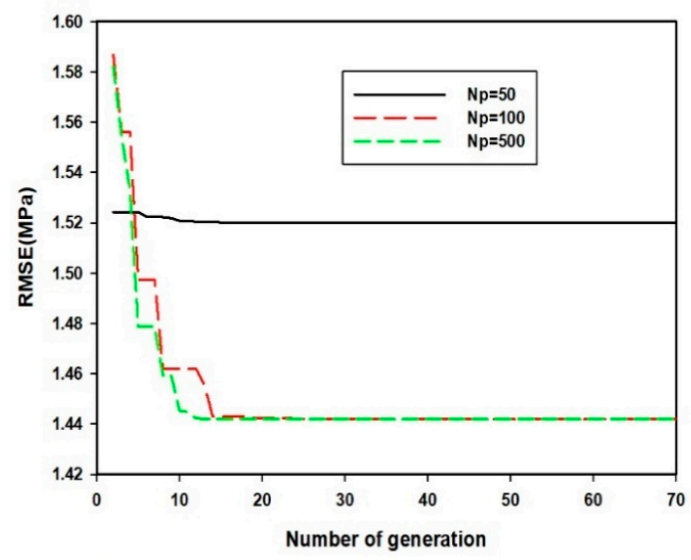

(c)

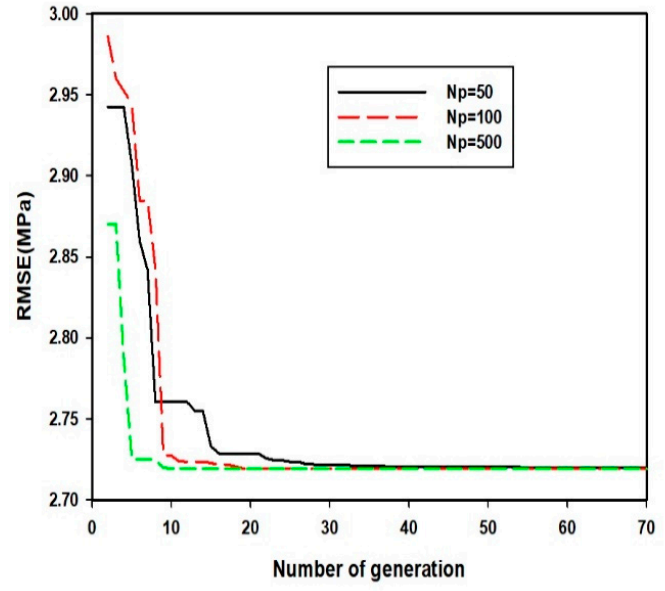

(b)

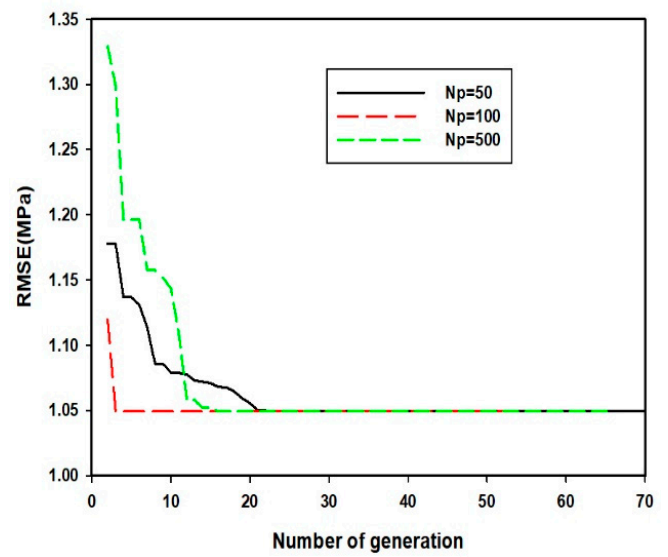

(d)

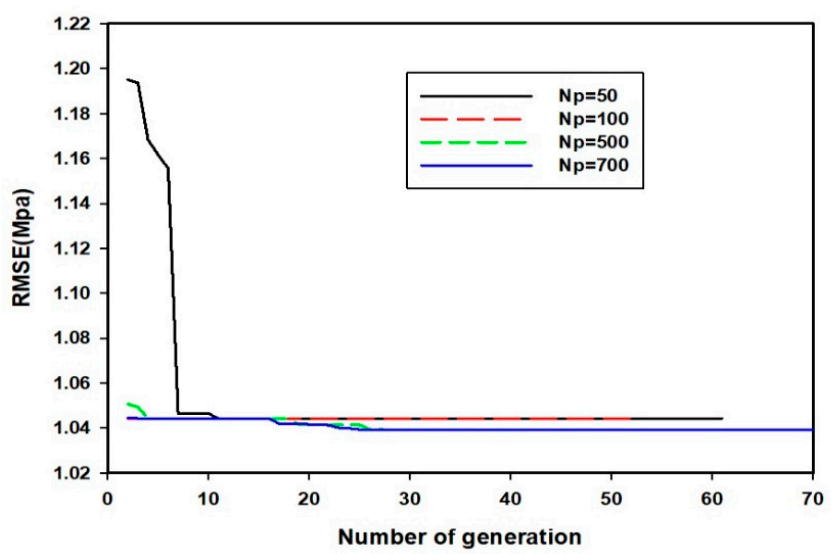

(e)

Figure 5. (a) Convergence of hybrid GA-SVR-CS28A to the number of generation at different pollution size (b) Convergence of hybrid GA-SVR-CS28B to the number of generation at different pollution size (c) Convergence of hybrid GA-SVR-CS28C to the number of generation at different pollution size (d) Convergence of hybrid GA-SVR-CS28D to the number of generation at different pollution size (e) Convergence of hybrid GA-SVR-CS28E to the number of generation at different pollution size. 


\subsubsection{Performance of Hybrid GA-SVR-CS28 at Each Developmental Stage}

The generalization and predictive strength of each of the 28-days compressive strength model are assessed using CC, RMSE, and MAE between the estimated and experimentally measured values for validation set of data. Figure 6 presents the comparison on the basis of correlation coefficient between the estimated strength and the measured values for the validation set of data. The developed hybrid GA-SVR-CS28A model that estimates the compressive strength of AALNM using six input descriptors which include binary binder variation $(x)$, sodium hydroxide molarity $(\mathrm{NH})$, curing temperature, sodium silicate to sodium hydroxide (NS/NH) ratio, alkaline to binder ratio (AK/B), and fine aggregate to binder $(\mathrm{FA} / \mathrm{BD})$ ratio, shows least performance as characterized with lowest value of CC. The significance of utilizing early-age strength and three-day strength to predict 28-day strength can be observed from the results of GA-SVR-CS28B and GA-SVR-CS28C as both models predict the 28 -day strength with $96.64 \%$ and $92.88 \%$ accuracy, respectively. This significantly saves time in predicting the 28-days compressive strength, utilizing the early-age strength.

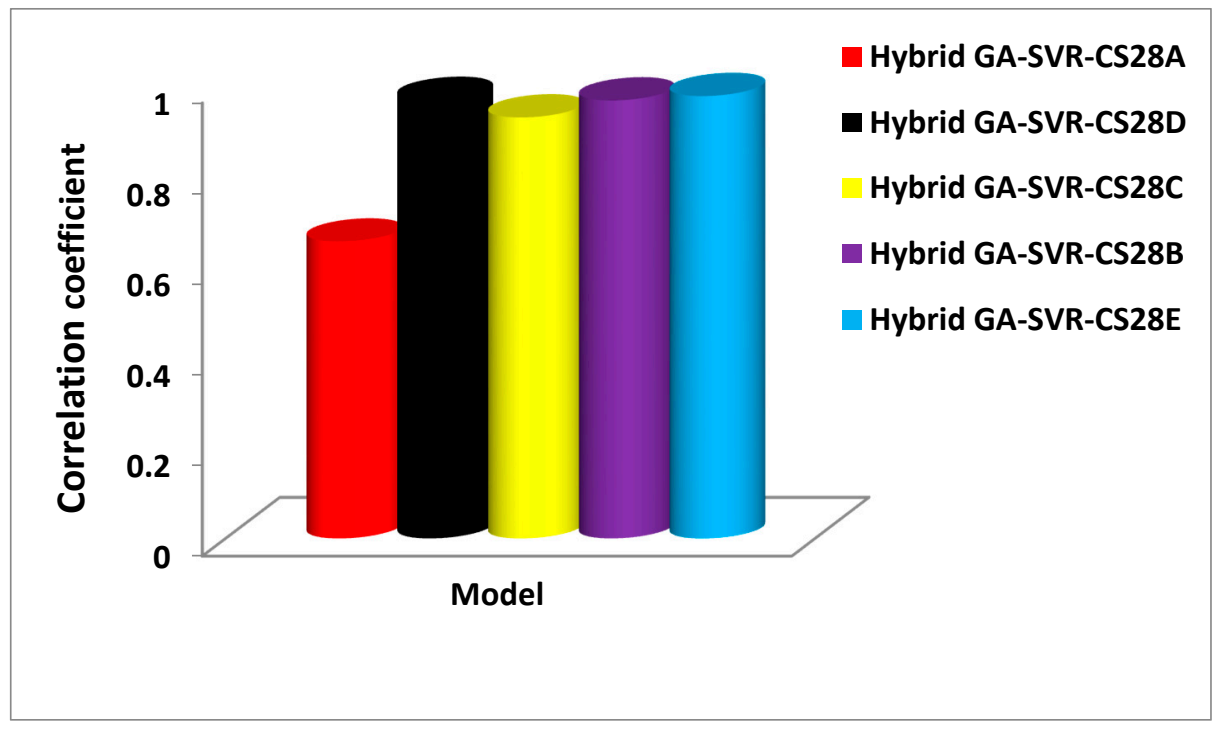

Figure 6. Performance comparison of the developed 28-day compressive strength model using the correlation coefficient performance metric.

However, hybrid GA-SVR-CS28B model that utilizes one-day strength performs better than GA-SVR-CS28C model that estimates 28-day strength using the three-day compressive strength with improvement of 3.89\%. Similarly, the developed hybrid GA-SVR-CS28C model that estimates 28-day strength using seven-day strength as input does this task with an accuracy of $96.75 \%$ while the hybrid GA-SVR-CS28D model that uses fourteen-days strength for its 28-day estimation is characterized with an accuracy of $97.6 \%$. Despite the high accuracy that characterizes each of these models, the developed hybrid GASVR-CS28C model that estimates 28-day strength using 14-day-strength shows the best performance. Figure 7 compares each of the developed 28-day compressive strength models on the basis of RMSE, while Figure 8 compares the model using MAE as a performance measuring parameter. 


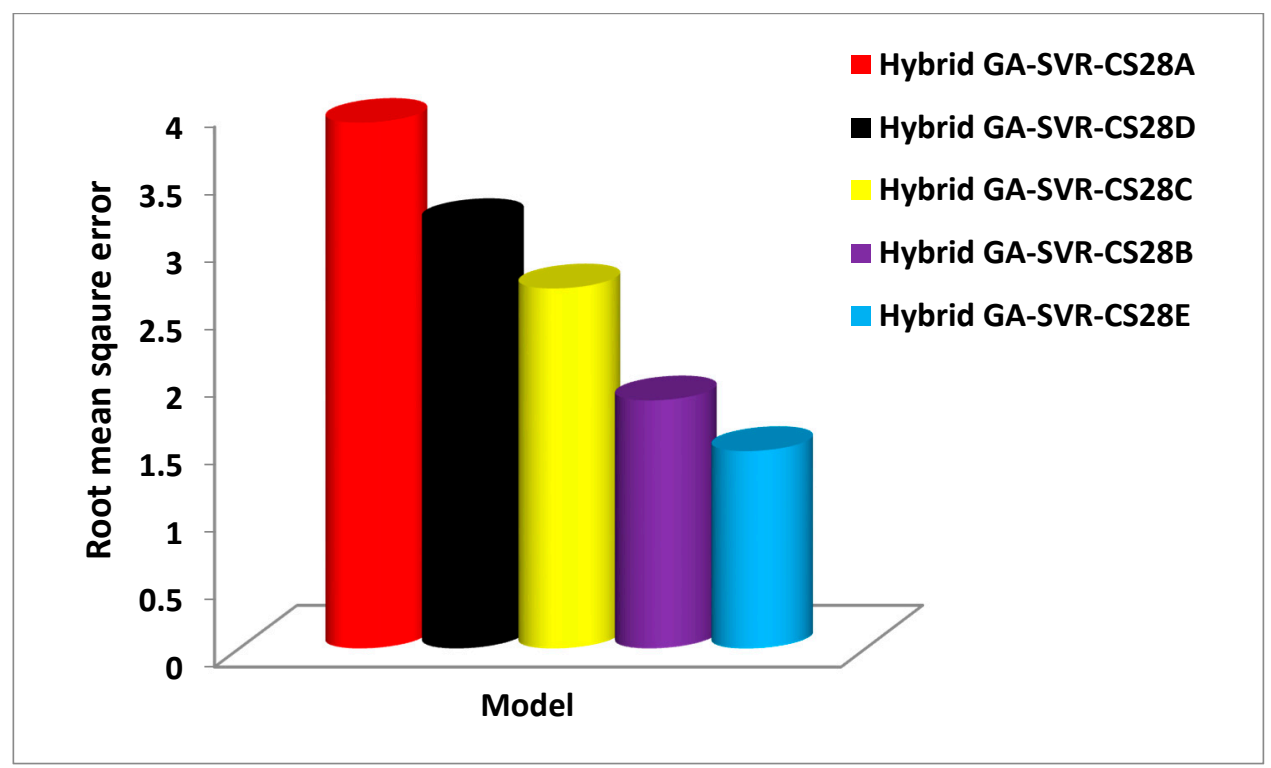

Figure 7. Performance comparison of the developed 28-day compressive strength model using the root mean square error performance metric.

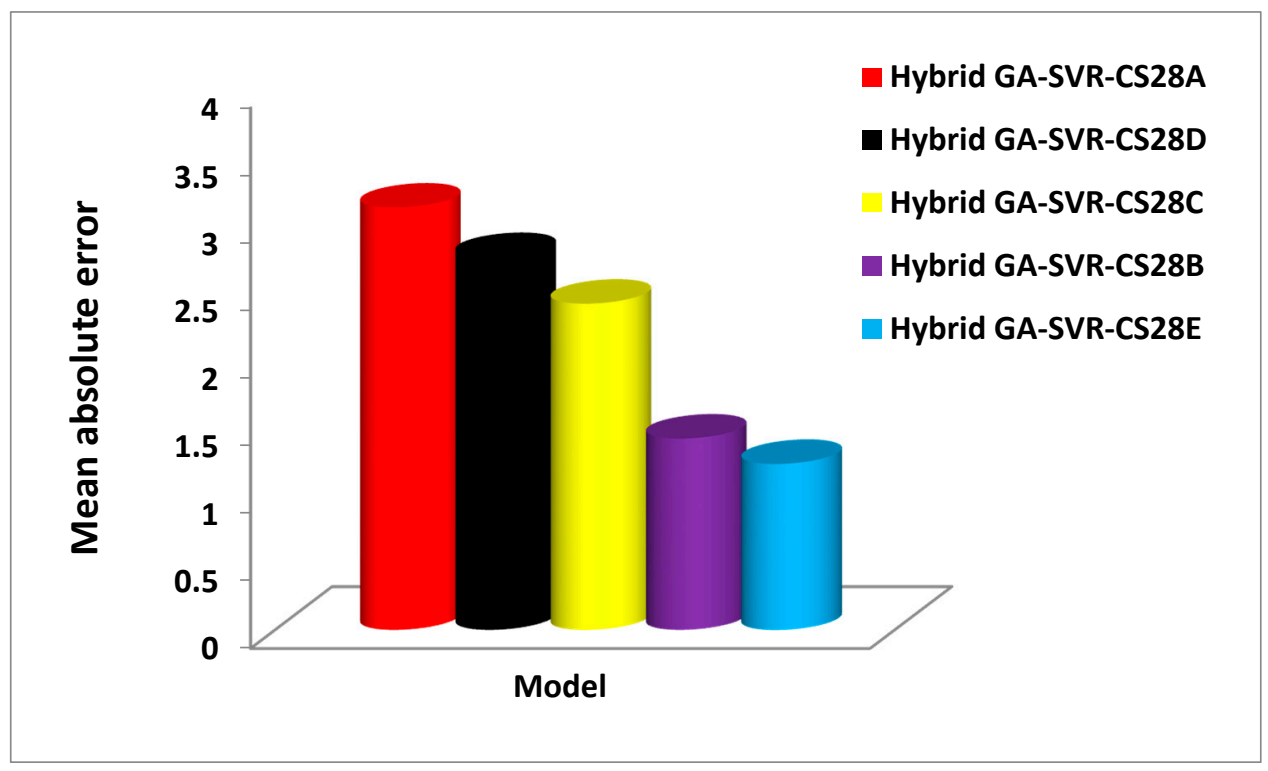

Figure 8. Performance comparison of the developed 28-day compressive strength model using the mean absolute performance metric.

The developed hybrid GA-SVR-CS28A model also shows the least performance with the highest RMSE and MAE as respectively presented in Figures 7 and 8. The developed hybrid GA-SVR-CS28B and GA-SVR-CS28C models estimate the 28-day compressive strength with very low RMSE of $1.8432 \mathrm{MPa}$ and $2.669 \mathrm{MPa}$ while MAE characterizing the models is $1.4143 \mathrm{MPa}$ and $2.4128 \mathrm{MPa}$. In the same vein, the RMSE for implementing the hybrid GA-SVR-CS28D and GA-SVR-CS28E models on validation set of data is $3.1514 \mathrm{MPa}$ and $1.4688 \mathrm{MPa}$, respectively, while the respective values of MAE are $2.758 .83 \mathrm{MPa}$ and $1.226 \mathrm{MPa}$. On the basis of the recorded errors, the developed hybrid GA-SVR-CS28B model performs better than model GA-SVR-CS28C, while the hybrid model GA-SVRCS28E shows the best performance. The error values and the coefficient of correlation for each of the developed 28-days compressive strength models are presented in Table 6. 
Table 6. Performance measuring parameters for the developed 28-days compressive strength model.

\begin{tabular}{cccc}
\hline Model & Training & Testing & Validation \\
\hline Hybrid GA-SVR-CS28A & & & \\
CC & 0.9684 & 0.9899 & 0.6548 \\
RMSE & 2.2452 & 0.8442 & 3.8911 \\
MAE & 1.7507 & 0.6908 & 3.1246 \\
CC & & & \\
RMSE & 0.9315 & 0.9779 & 0.9664 \\
MAE & 2.1655 & 2.7192 & 1.8432 \\
CC & 1.5296 & 2.4756 & 1.4143 \\
RMSE & & & \\
MAE & 0.9502 & 0.9958 & 2.9288 \\
Hybrid GA-SVR-CS28C & 1.9366 & 1.442 & 2.4128 \\
CC & 1.4209 & 1.1161 & 0.9675 \\
RMSE & & & 3.1514 \\
MAE & 0.9392 & 0.9539 & 2.7583 \\
Hybrid GA-SVR-CS28D & 4.1867 & 1.0493 & \\
CC & 3.087 & 0.8511 & 0.976 \\
RMSE & & & 1.4688 \\
MAE & 0.9947 & 0.9945 & 1.226 \\
\hline
\end{tabular}

3.4. Comparison between the Experimentally Measured 28-Day Compressive Strength and the Outcomes of the Developed Hybrid GA-SVR-CS28 Model

Comparison between the experimentally measured 28-day compressive strength and the estimated values as obtained from each of the developed models are presented in Figures 9-11. The actual values of the estimated compressive strength for each of the developed 28-day compressive strength model are provided in Appendix B. In mixtures M1 to M9, presented in Figure 9, the results of each of the model are very close to the experimental values, except the estimates of the hybrid GA-SVR-CSD for mixture M6 to M9 that show slight deviation from the measured values. For mixtures M10 to M18, presented in Figure 10, the results of each of the developed hybrid models agree excellently well with the measured values, except the results of hybrid GA-SVR-CS28A for mixtures M24 to M26 as shown in Figure 11. In all, the results of each of the models are excellent, while some models perform better than the others.

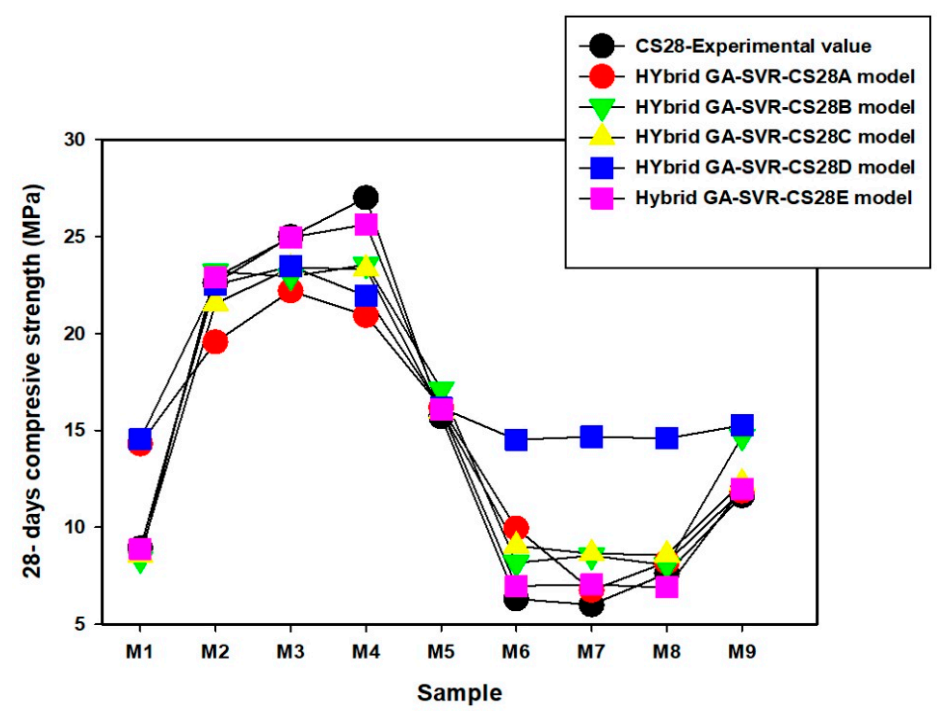

Figure 9. Comparison between experimentally measured 28-day compressive strength and the results of the developed models for mixtures M1 to M9. 


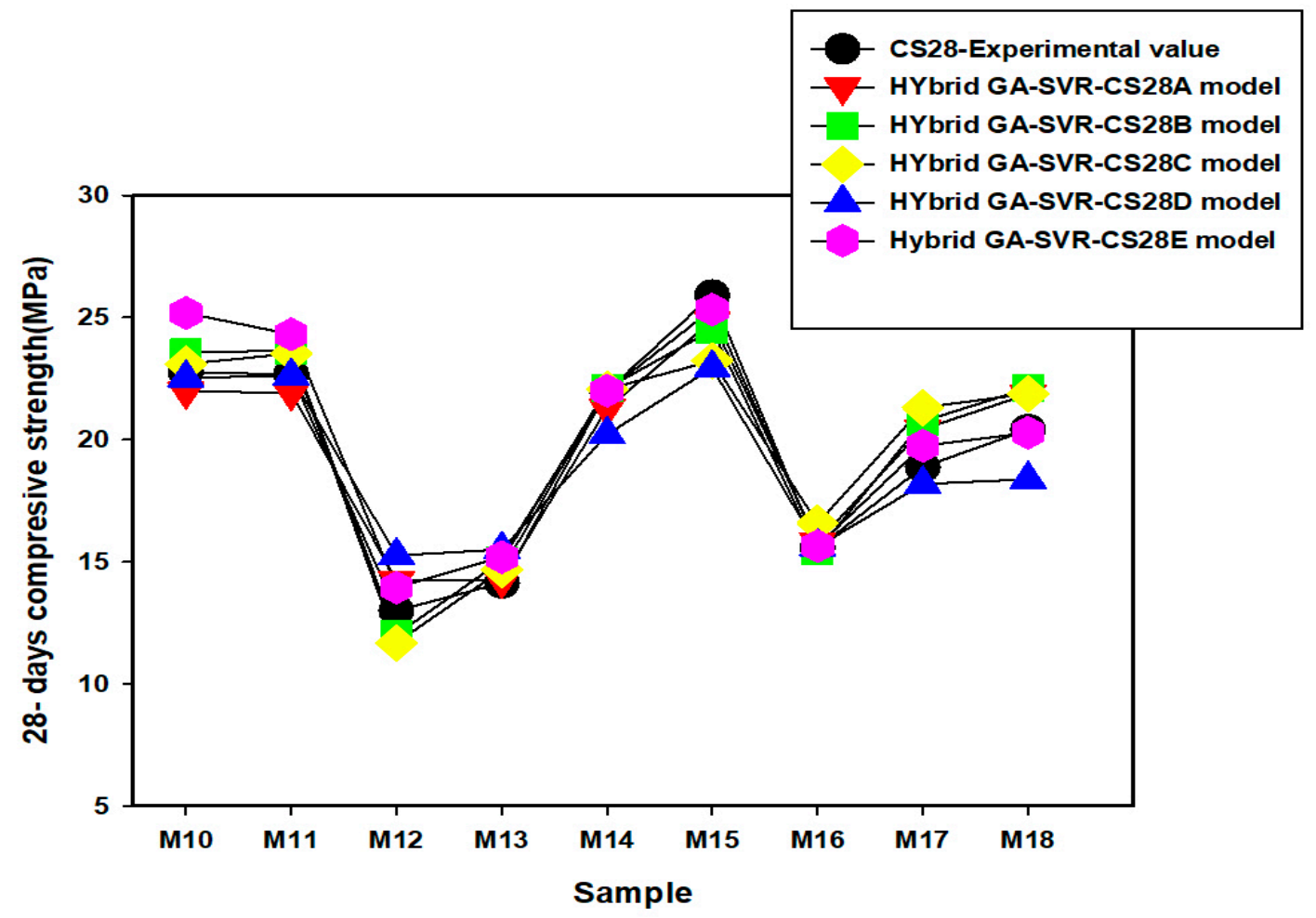

Figure 10. Comparison between experimentally measured 28-day compressive strength and the results of the developed models for mixtures M10 to M18.

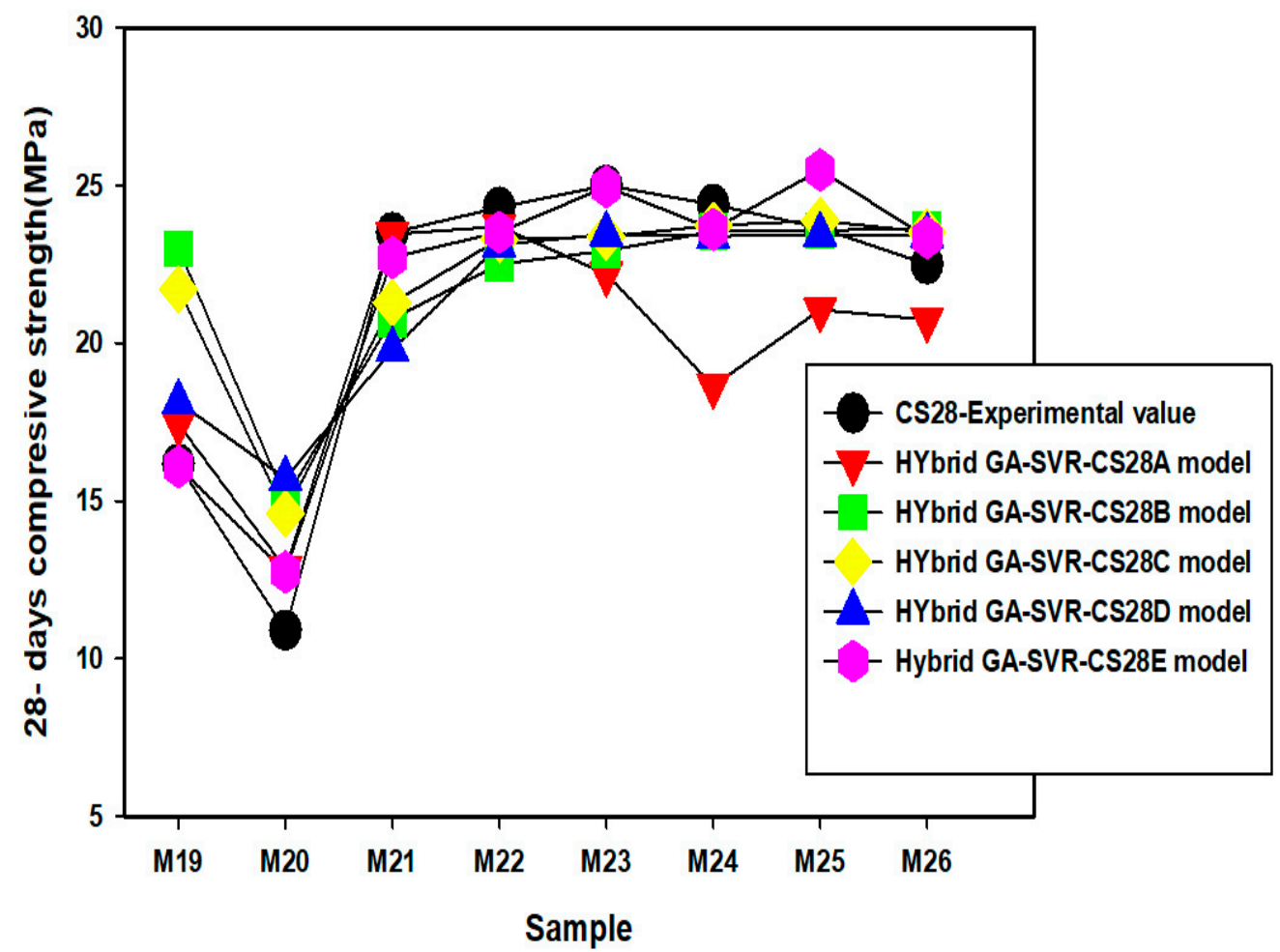

Figure 11. Comparison between experimentally measured 28-days compressive strength and the results of the developed models for mixtures M19 to M26. 
3.5. Modeling the Influence of Constituents of AALNM on the Compressive Strength Using the Developed Hybrid GA-SVR-CS28A Model

In order to further validate and justify the reported potentials and excellence of the developed 28-day compressive strength model, the influence of binary binder ratio on the 28-day strength of AALNM was investigated at different molarity of sodium hydroxide using the developed hybrid GA-SVR-CS28A. The results of investigation are presented in Figure 12, keeping the curing temperature $(\mathrm{T})$, sodium silicate to sodium hydroxide $(\mathrm{NS} / \mathrm{NH})$ ratio, fine aggregate to binder ratio $(\mathrm{FA} / \mathrm{B})$, and alkaline to binder ratio $(\mathrm{AK} / \mathrm{B})$ at $75^{\circ} \mathrm{C}, 1,2$, and 0.5 , respectively. 28 -days compressive strength decreases in a parabolic form characterized with minimum point as the ratio of binary binder increases for lower sodium hydroxide molarity of 4,6 , and 8 . A sudden rise in 28-day strength was observed when the molarity of sodium hydroxide was $10 \mathrm{M}$ after which further increase in the molarity decreased the strength. It should be noted that the developed hybrid GA-SVRCS28A model was only supplied with input descriptors while the model implements its acquired and saved support vectors during the training phase of model development for its estimation as presented in Figure 12. The result of similar investigation is revealed in Figure 13 where the dependence of the 28-day strength on fine aggregate to binder ratio at different sodium silicate to sodium hydroxide (NS/NH) ratio is conducted. The maximum 28-day achievable strength increases with an increase in NS/NH ratio and begins to decrease thereafter.

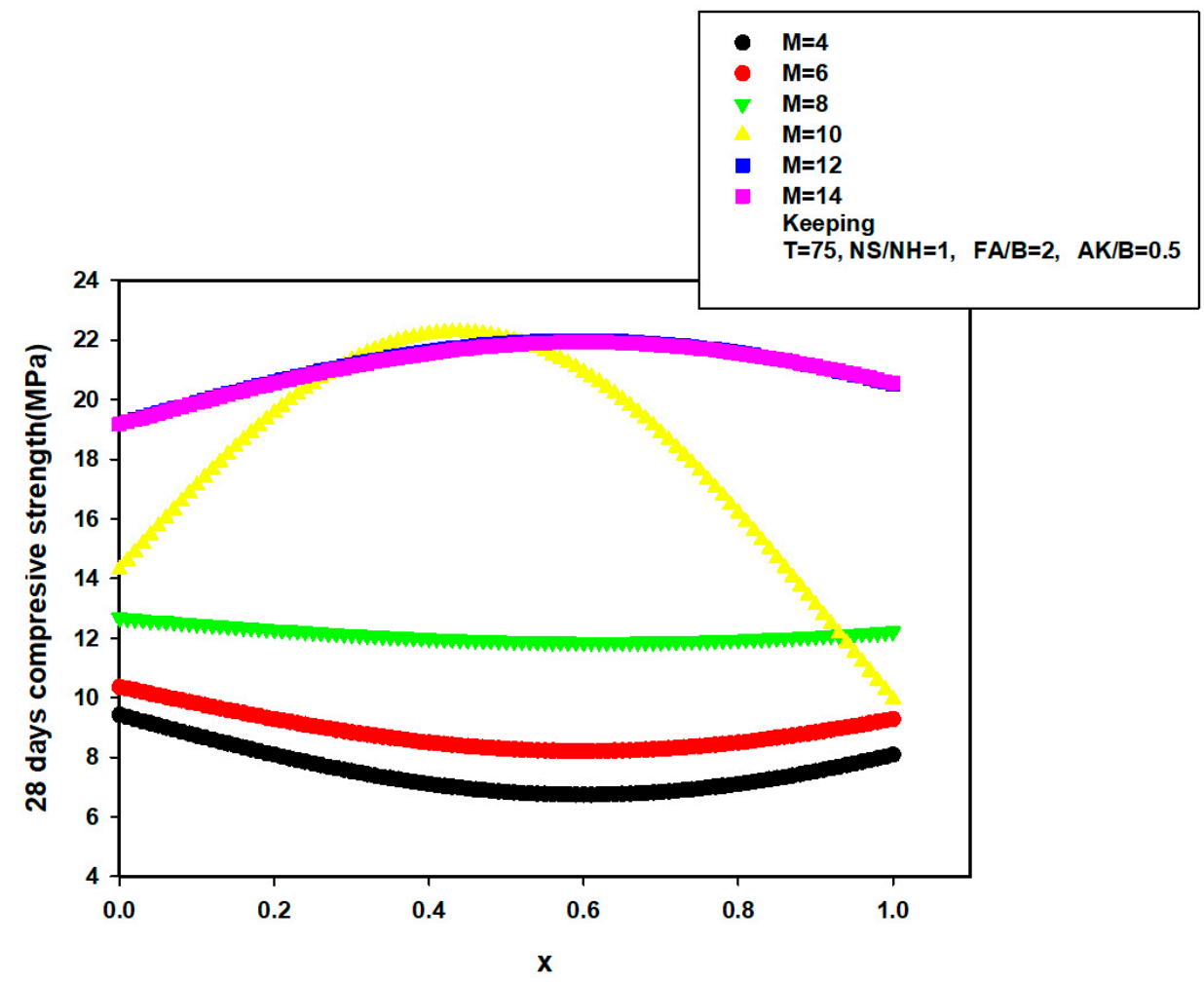

Figure 12. Dependence of 28-day compressive strength of AANLM at various molarity on the binder ratio using the developed hybrid GA-SVR-CS28A model. 


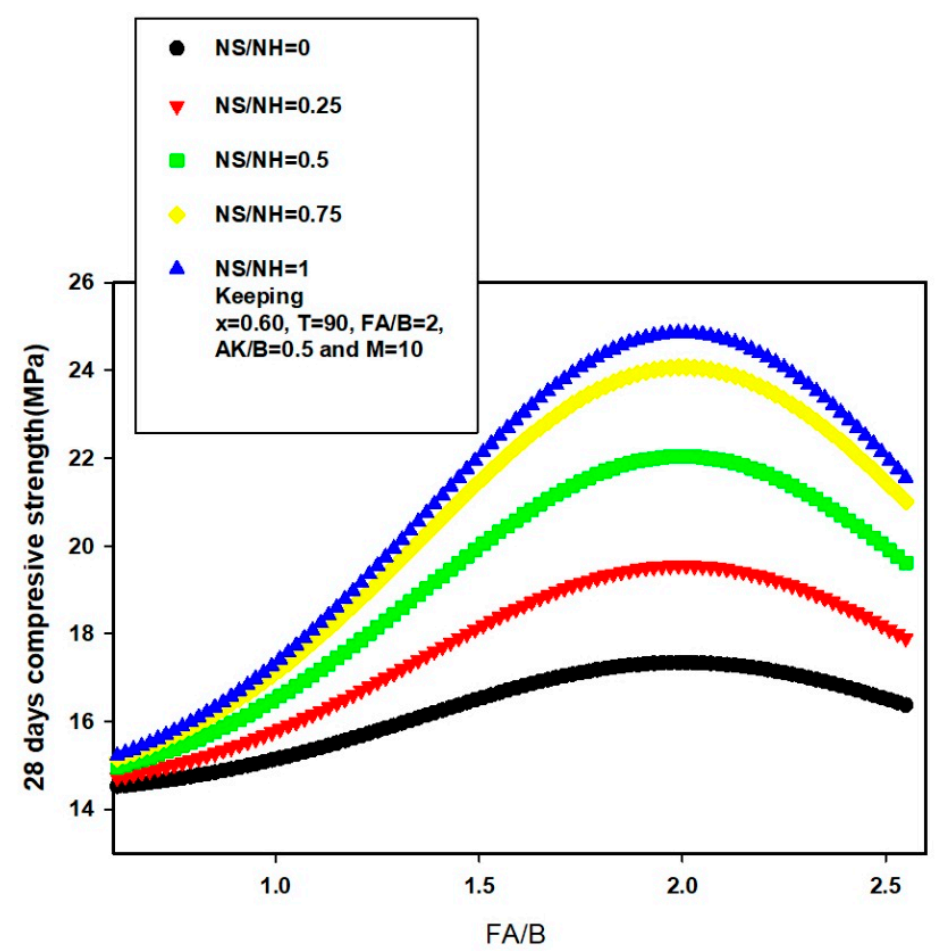

Figure 13. Dependence of 28-day compressive strength of AANLM at various molarity NS/NH ratio on the ratio of FA/B using the developed hybrid GA-SVR-CS28A model.

\section{Conclusions}

The compressive strength of alkali-activated natural pozzolan/limestone powder mortar (AALNM) is modelled through hybridization of support vector regression (SVR) and genetic algorithm (GA) using binary binder variation, sodium hydroxide molarity $(\mathrm{NH})$, curing temperature, sodium silicate to sodium hydroxide (NS/NH), alkaline to binder ratio $[\mathrm{AK} / \mathrm{B}]$, and fine aggregate to binder ratio (FA/BD) as descriptive features. The developed hybrid GA-SVR-CS1, GA-SVR-CS3, and GA-SVR-CS14 models are capable of estimating one-day strength, three-day strength, seven-day strength, and 14-day strength of AALNM, respectively, with accuracy of $96.64 \%, 90.84 \%$, and $93.4 \%$ measured on the basis of correlation coefficient between the estimated strength and experimentally measured values. The developed 28-day strength models include the hybrid GA-SVR-CS28A model with six descriptive features, GA-SVR-CS28B model that uses one-day strength, GA-SVR-CS28C model that employs three-day strength, GA-SVR-CS28D model that implements seven-day strength and GA-SVR-CS28E that estimates 28-day strength using 14-day strength as its input. Each of the developed 28-day strength is characterized with excellent predictive and generalization strength. The developed hybrid models were also employed to model the behavior of AALNM and the obtained behavior agree perfectly well with the experimental data. The hybrid models proposed and developed in this research are meritorious because of their strengths, accuracy, and precision, coupled with their ability to save appreciable experimental time and other valuable resources.

Author Contributions: Conceptualization, A.A.A., M.A.M.A., and M.I.; methodology, K.A.A.A.-S. and M.M.; software, H.O.S. and T.O.O.; validation K.A.A.A.-S., A.A.A. and T.O.O.; formal analysis, A.A.A., H.O.S., H.D.M. and M.A.M.A.; investigation, A.A.A. and H.D.M.; resources, M.M. and M.I.; data curation, T.O.O. and H.O.S.; writing-original draft preparation, K.A.A.A.-S., A.A.A., T.O.O. and H.O.S.; writing-review and editing, M.M., M.I., M.A.M.A.; visualization, H.O.S., T.O.O. and A.A.A.; supervision, M.I. and M.A.M.A.; project administration, M.M. and K.A.A.A.-S.; funding acquisition, M.A.M.A., K.A.A.A.-S. and M.M. All authors have read and agreed to the published version of the manuscript. 
Funding: This research was funded by Research Management Centre (RMC), Universiti Teknologi Malaysia (UTM), Ministry of higher education, grant number R.J 130000.7851.5F066 \& Q.J 130000.2551. $21 \mathrm{~h} 67$ and The APC was funded by all Authors.

Institutional Review Board Statement: This article does not contain any studies with animals performed by any of the authors. Not applicable.

Informed Consent Statement: This article does not contain studies with human participants. Not applicable.

Data Availability Statement: The raw data required to reproduce these findings are available in the cited references in Section 2.3 of this manuscript.

Acknowledgments: The authors gratefully acknowledge the support from the Universiti Teknologi Malaysia (UTM), Johor Bahru, Malaysia, the University of Hafr Al Batin, (UHB), Hafr Al Batin, Saudi Arabia and King Fahd University of Petroleum and Minerals (KFUPM), Dhahran, Saudi Arabia.

Conflicts of Interest: The authors declare that they have no conflict of interest.

Appendix A

Table A1. Experimental and actual values of estimated early-day compressive strength models.

\begin{tabular}{|c|c|c|c|c|c|c|}
\hline Mix & $\begin{array}{c}\text { Experimentally } \\
\text { Measured } \\
\text { CS } 1 \text { (MPa) }\end{array}$ & $\begin{array}{c}\text { Hybrid } \\
\text { GA-SVR } \\
\text { CS1 (Mpa) }\end{array}$ & $\begin{array}{c}\text { Experimentally } \\
\text { Measured } \\
\text { CS3 (MPa) }\end{array}$ & $\begin{array}{c}\text { Hybrid } \\
\text { GA-SVR } \\
\text { CS3 (Mpa) }\end{array}$ & $\begin{array}{c}\text { Experimentally } \\
\text { Measured } \\
\text { CS-14 (MPa) }\end{array}$ & $\begin{array}{c}\text { Hybrid } \\
\text { GA-SVR- } \\
\text { CS14 (MPa) }\end{array}$ \\
\hline M1 & 4.430 & 7.351 & 4.850 & 5.600 & 5.200 & 19.904 \\
\hline M2 & 18.620 & 15.926 & 18.680 & 16.770 & 21.850 & 19.639 \\
\hline M3 & 20.720 & 21.579 & 23.890 & 23.309 & 24.300 & 19.292 \\
\hline M4 & 20.900 & 19.498 & 23.950 & 22.378 & 25.180 & 18.870 \\
\hline M5 & 12.870 & 12.546 & 13.980 & 15.079 & 14.500 & 18.387 \\
\hline M6 & 5.330 & 6.980 & 5.570 & 7.253 & 5.800 & 17.857 \\
\hline M7 & 4.320 & 5.726 & 4.430 & 5.218 & 4.790 & 11.022 \\
\hline M8 & 4.730 & 6.098 & 4.850 & 5.600 & 5.030 & 5.935 \\
\hline M9 & 7.850 & 12.657 & 8.360 & 8.791 & 9.010 & 9.533 \\
\hline M10 & 20.150 & 18.821 & 24.310 & 23.287 & 24.730 & 24.361 \\
\hline M11 & 21.550 & 20.094 & 23.560 & 22.605 & 24.670 & 24.116 \\
\hline M12 & 6.850 & 8.026 & 7.730 & 13.080 & 10.550 & 16.778 \\
\hline M13 & 10.680 & 12.657 & 12.470 & 13.080 & 12.760 & 13.174 \\
\hline M14 & 17.060 & 16.012 & 19.340 & 13.080 & 20.360 & 16.778 \\
\hline M15 & 23.350 & 21.730 & 24.130 & 23.124 & 24.370 & 23.631 \\
\hline M16 & 9.580 & 10.530 & 14.430 & 14.350 & 13.170 & 18.625 \\
\hline M17 & 15.380 & 14.600 & 18.320 & 18.326 & 18.860 & 18.806 \\
\hline M18 & 17.060 & 16.012 & 19.130 & 21.657 & 19.040 & 18.854 \\
\hline M19 & 18.320 & 17.608 & 18.920 & 18.559 & 18.800 & 18.854 \\
\hline M20 & 10.900 & 14.628 & 12.340 & 13.097 & 13.410 & 18.806 \\
\hline M21 & 15.400 & 13.837 & 18.250 & 17.926 & 20.100 & 20.680 \\
\hline M22 & 17.600 & 15.790 & 20.640 & 20.383 & 22.400 & 20.121 \\
\hline M23 & 18.200 & 18.285 & 21.220 & 22.183 & 23.600 & 19.512 \\
\hline M24 & 19.500 & 18.285 & 21.320 & 20.779 & 22.800 & 18.216 \\
\hline M25 & 20.300 & 19.415 & 22.180 & 22.146 & 23.650 & 18.870 \\
\hline M26 & 21.500 & 19.415 & 23.600 & 22.473 & 22.840 & 18.870 \\
\hline
\end{tabular}




\section{Appendix B}

Table A2. Experimental and actual values of estimated 28-day compressive strength models.

\begin{tabular}{|c|c|c|c|c|c|c|}
\hline Mix & $\begin{array}{c}\text { Experimentally } \\
\text { Measured } \\
\text { CS } 28 \text { (MPa) }\end{array}$ & $\begin{array}{c}\text { Hybrid } \\
\text { GA-SVR } \\
\text { CS-28A (MPa) }\end{array}$ & $\begin{array}{c}\text { Hybrid } \\
\text { GA-SVR } \\
\text { CS-28B (MPa) }\end{array}$ & $\begin{array}{c}\text { Hybrid } \\
\text { GA-SVR } \\
\text { CS-28C (MPa) }\end{array}$ & $\begin{array}{c}\text { Hybrid } \\
\text { GA-SVR } \\
\text { CS-28D (MPa) }\end{array}$ & $\begin{array}{c}\text { Hybrid } \\
\text { GA-SVR } \\
\text { CS-28E (MPa) }\end{array}$ \\
\hline M1 & 8.920 & 14.300 & 8.363 & 8.577 & 14.540 & 8.871 \\
\hline M2 & 22.600 & 19.558 & 23.197 & 21.550 & 22.521 & 22.898 \\
\hline M3 & 25.000 & 22.197 & 22.931 & 23.374 & 23.464 & 24.961 \\
\hline M4 & 27.000 & 20.925 & 23.547 & 23.341 & 21.942 & 25.623 \\
\hline M5 & 15.700 & 16.191 & 17.124 & 15.981 & 16.163 & 16.068 \\
\hline M6 & 6.300 & 9.947 & 8.162 & 9.041 & 14.517 & 6.970 \\
\hline M7 & 6.000 & 6.746 & 8.540 & 8.631 & 14.666 & 7.040 \\
\hline M8 & 7.610 & 8.207 & 8.040 & 8.577 & 14.581 & 6.890 \\
\hline M9 & 11.620 & 11.860 & 14.673 & 12.284 & 15.252 & 11.983 \\
\hline M10 & 22.750 & 21.983 & 23.580 & 23.104 & 22.543 & 25.191 \\
\hline M11 & 22.690 & 21.924 & 23.648 & 23.533 & 22.615 & 24.321 \\
\hline M12 & 13.000 & 14.230 & 12.023 & 11.693 & 15.253 & 13.941 \\
\hline M13 & 14.130 & 14.230 & 15.040 & 14.663 & 15.505 & 15.190 \\
\hline M14 & 22.000 & 21.292 & 22.107 & 22.066 & 20.217 & 22.007 \\
\hline M15 & 25.920 & 24.855 & 24.499 & 23.231 & 22.946 & 25.333 \\
\hline M16 & 15.570 & 15.819 & 15.439 & 16.581 & 15.621 & 15.642 \\
\hline M17 & 18.880 & 20.433 & 20.756 & 21.316 & 18.193 & 19.757 \\
\hline M18 & 20.420 & 21.869 & 22.107 & 21.887 & 18.380 & 20.286 \\
\hline M19 & 16.170 & 17.439 & 23.011 & 21.722 & 18.134 & 16.082 \\
\hline M20 & 10.900 & 12.845 & 15.056 & 14.595 & 15.702 & 12.743 \\
\hline M21 & 23.500 & 23.453 & 20.776 & 21.272 & 19.805 & 22.719 \\
\hline M22 & 24.300 & 23.693 & 22.501 & 23.294 & 23.118 & 23.515 \\
\hline M23 & 25.000 & 22.197 & 22.931 & 23.374 & 23.464 & 24.961 \\
\hline M24 & 24.400 & 18.649 & 23.541 & 23.733 & 23.392 & 23.614 \\
\hline M25 & 23.650 & 21.063 & 23.573 & 23.884 & 23.447 & 25.492 \\
\hline M26 & 22.500 & 20.747 & 23.633 & 23.516 & 23.411 & 23.345 \\
\hline
\end{tabular}

\section{References}

1. UN Environment; Scrivener, K.L.; John, V.M.; Gartner, E.M. Eco-efficient cements: Potential economically viable solutions for a low- $\mathrm{CO}_{2}$ cement-based materials industry. Cem. Concr. Res. 2018, 114, 2-26. [CrossRef]

2. Van Damme, H. Concrete material science: Past, present, and future innovations. Cem. Concr. Res. 2018, 112, 5-24. [CrossRef]

3. Imbabi, M.S.; Carrigan, C.; McKenna, S. Trends and developments in green cement and concrete technology. Int. J. Sustain. Built Environ. 2012, 1, 194-216. [CrossRef]

4. CEMBUREAU. Activity Report 2015; CEMBUREAU: Brussels, Belgium, 2015.

5. Damtoft, J.S.; Lukasik, J.; Herfort, D.; Sorrentino, D.; Gartner, E.M. Sustainable development and climate change initiatives. Cem. Concr. Res. 2008, 38, 115-127. [CrossRef]

6. Andrew, R.M. Global $\mathrm{CO}_{2}$ emissions from cement production. Earth Syst. Sci. Data 2017, 10, 1-52.

7. Rafiei, M.H. Advanced Neural Network and Machine Learning Models for Construction, Materials and Structural Engineering. Ph.D. Thesis, The Ohio State University, Columbus, OH, USA, 2016; p. 228.

8. Provis, J.L. Alkali avtivated materials. Cem. Concr. Res. 2014, 114, 40-48. [CrossRef]

9. Najimi, M.; Ghafoori, N.; Sharbaf, M. Alkali-activated natural pozzolan/slag mortars: A parametric study. Constr. Build. Mater. 2018, 164, 625-643. [CrossRef] 
10. Luukkonen, T.; Abdollahnejad, Z.; Yliniemi, J.; Kinnunen, P.; Illikainen, M. One-part alkali-activated materials: A review. Cem. Concr. Res. 2018, 103, 21-34. [CrossRef]

11. Glasby, T.; Day, J.; Genrich, R.; Aldred, J. EFC geopolymer concrete aircraft pavements at Brisbane West Wellcamp Airport. Concrete 2015, 11, 1-9.

12. Van Deventer, J.S.J.; Provis, J.L.; Duxson, P. Technical and commercial progress in the adoption of geopolymer cement. Miner. Eng. 2012, 29, 89-104. [CrossRef]

13. McIntosh, A.; Lawther, S.E.M.; Kwasny, J.; Soutsos, M.N.; Cleland, D.; Nanukuttan, S. Selection and characterisation of geological materials for use as geopolymer precursors. Adv. Appl. Ceram. 2015, 114, 378-385. [CrossRef]

14. Patel, R.; Kinney, F.; Schumacher, G. Green concrete using 100\% fly ash based hydraulic binder. Int. Concr. Sustain. Conf. 2012, 5 , $1-15$.

15. Cross, D.; Stephens, J.; Vollmer, J. Structural Applications of 100 Percent Fly Ash Concrete. Available online: https://p2infohouse. org/ref/45/44859.pdf (accessed on 4 April 2021).

16. Najimi, M.; Sobhani, J.; Ahmadi, B.; Shekarchi, M. An experimental study on durability properties of concrete containing zeolite as a highly reactive natural pozzolan. Constr. Build. Mater. 2012, 35, 1023-1033. [CrossRef]

17. Ibrahim, M.; Johari, M.A.M.; Rahman, M.K.; Maslehuddin, M. Effect of alkaline activators and binder content on the properties of natural pozzolan-based alkali activated concrete. Constr. Build. Mater. 2017, 147, 648-660. [CrossRef]

18. Karim, M.R.; Zain, M.F.M.; Jamil, M.; Lai, F.C. Fabrication of a non-cement binder using slag, palm oil fuel ash and rice husk ash with sodium hydroxide. Constr. Build. Mater. 2013, 49, 894-902. [CrossRef]

19. Salami, B.A.; Johari, M.A.M.; Ahmad, Z.A.; Maslehuddin, M. Impact of added water and superplasticizer on early compressive strength of selected mixtures of palm oil fuel ash-based engineered geopolymer composites. Constr. Build. Mater. 2016, 109, 198-206. [CrossRef]

20. Kubba, Z.; Huseien, G.F.; Sam, A.R.M.; Shah, K.W.; Asaad, M.A.; Ismail, M.; Tahir, M.M.; Mirza, J. Impact of curing temperatures and alkaline activators on compressive strength and porosity of ternary blended geopolymer mortars. Case Stud. Constr. Mater. 2018, 9, e00205. [CrossRef]

21. Salami, B.A.; Johari, M.A.M.; Ahmad, Z.A.; Maslehuddin, M.; Adewumi, A.A. Impact of $\mathrm{Al}(\mathrm{OH})_{3}$ addition to POFA on the compressive strength of POFA alkali-activated mortar. Constr. Build. Mater. 2018, 190, 65-82. [CrossRef]

22. Yusuf, M.O. Performance of slag blended alkaline activated palm oil fuel ash mortar in sulfate environments. Constr. Build. Mater. 2015, 98, 417-424. [CrossRef]

23. Najamuddin, S.K.; Johari, M.A.M.; Maslehuddin, M.; Yusuf, M.O. Synthesis of low temperature cured alkaline activated silicomanganese fume mortar. Constr. Build. Mater. 2019, 200, 387-397. [CrossRef]

24. Deb, P.S.; Nath, P.; Sarker, P.K. The effects of ground granulated blast-furnace slag blending with fly ash and activator content on the workability and strength properties of geopolymer concrete cured at ambient temperature. Mater. Des. 2014, 62, 32-39. [CrossRef]

25. Criado, M.; Aperador, W.; Sobrados, I. Microstructural and mechanical properties of alkali activated Colombian raw materials. Materials 2016, 9, 158. [CrossRef]

26. Lee, N.K.; Lee, H.K. Setting and mechanical properties of alkali-activated fly ash/slag concrete manufactured at room temperature. Constr. Build. Mater. 2013, 47, 1201-1209. [CrossRef]

27. Sinthaworn, S.; Nimityongskul, P. Effects of temperature and alkaline solution on electrical conductivity measurements of pozzolanic activity. Cem. Concr. Compos. 2011, 33, 622-627. [CrossRef]

28. Topçu, I.B.; Toprak, M.U.; Uygunoğlu, T. Durability and microstructure characteristics of alkali activated coal bottom ash geopolymer cement. J. Clean. Prod. 2014, 81, 211-217. [CrossRef]

29. Adesanya, E.; Ohenoja, K.; Luukkonen, T.; Kinnunen, P.; Illikainen, M. One-part geopolymer cement from slag and pretreated paper sludge. J. Clean. Prod. 2018, 185, 168-175. [CrossRef]

30. Jang, J.G.; Lee, N.K.; Lee, H.K. Fresh and hardened properties of alkali-activated fly ash/slag pastes with superplasticizers. Constr. Build. Mater. 2014, 50, 169-176. [CrossRef]

31. Adewumi, A.A.; Owolabi, T.O.; Alade, I.O.; Olatunji, S.O. Estimation of physical, mechanical and hydrological properties of permeable concrete using computational intelligence approach. Appl. Soft Comput. J. 2016, 42, 342-350. [CrossRef]

32. Cortes, C.; Vapnik, V. Support vector networks. Mach. Learn. 1995, 20, 273-297. [CrossRef]

33. Owolabi, T.O. Development of a particle swarm optimization based support vector regression model for titanium dioxide band gap characterization. J. Semicond. 2019, 40, 022803. [CrossRef]

34. Owolabi, T.O.; Gondal, M.A. Development of hybrid extreme learning machine based chemo-metrics for precise quantitative analysis of LIBS spectra using internal reference pre-processing method. Anal. Chim. Acta 2018, 1030, 33-41. [CrossRef]

35. Owolabi, T.O.; Gondal, M.A. Quantitative analysis of LIBS spectra using hybrid chemometric models through fusion of extreme learning machines and support vector regression. J. Intell. Fuzzy Syst. 2018, 35, 1-10. [CrossRef]

36. Owolabi, T.O.; Akande, K.O.; Olatunji, S.O.; Aldhafferi, N. Ensemble-based support vector regression with gravitational search algorithm optimization for estimating magnetic relative cooling power of manganite refrigerant in magnetic refrigeration application. J. Supercond. Nov. Magn. 2018, 32, 2107-2118. [CrossRef]

37. Oloore, L.E.; Owolabi, T.O.; Fayose, S.; Adegoke, M.; Akande, K.O.; Olatunji, S.O. Modeling of semiconductors refractive indices using hybrid chemometric model. Model. Meas. Control. A 2018, 91, 95-103. [CrossRef] 
38. Owolabi, T.O.; Akande, K.O.; Olatunji, S.O. Computational intelligence method of estimating solid-liquid interfacial energy of materials at their melting temperatures. J. Intell. Fuzzy Syst. 2016, 31, 519-527. [CrossRef]

39. Baser, F.; Apaydin, A. Hybrid fuzzy support vector regression analysis. J. Intell. Fuzzy Syst. 2015, 28, 2037-2045. [CrossRef]

40. Suleiman, M.A.; Owolabi, T.O.; Adeyemo, H.B.; Olatunji, S.O. Modeling of autoignition temperature of organic energetic compounds using hybrid intelligent method. Process. Saf. Environ. Prot. 2018, 120, 79-86. [CrossRef]

41. Vapnik, V.M. Statistical Learning Theory; Wiley-Interscience: New York, NY, USA, 1998.

42. Niu, J.; Chen, J.; Xu, Y. Twin support vector regression with Huber loss. J. Intell. Fuzzy Syst. 2017, 32, 4247-4258. [CrossRef]

43. Al-Anazi, A.F.; Gates, I.D. Support vector regression to predict porosity and permeability: Effect of sample size. Comput. Geosci. 2012, 39, 64-76. [CrossRef]

44. Smola, A.; Scholköpf, B. A tutorial on support vector regression. Stat. Comput. 2004, 14, 199-222. [CrossRef]

45. Owolabi, T.O. Modeling the magnetocaloric effect of manganite using hybrid genetic and support vector regression algorithms. Phys. Lett. A 2019, 383, 1782-1790. [CrossRef]

46. Crone, S.F.; Guajardo, J.; Weber, R. The impact of preprocessing on support vector regression and neural networks in time series prediction. Conf. Data Min. 2006, 3, 37-42.

47. Owolabi, T.O. Determination of the velocity of detonation of primary explosives using genetically optimized support vector regression. Propellants Explos. Pyrotech. 2019, 44, 1-12. [CrossRef]

48. Holland, J.H. Genetic algorithms. Sci. Am. 1992, 267, 66-73. [CrossRef]

49. Salami, H.O.; Mamman, E.Y. A genetic algorithm for allocating project supervisors to students. Int. J. Intell. Syst. Appl. 2016, 8, 51-59. [CrossRef]

50. ASTM International. ASTM Standard C33, 2003. In Specification for Concrete Aggregates; ASTM International: West Conshohocken, PA, USA, 2003.

51. American Society of Testing Materials. Standard Specification for Portland Cement; ASTM: West Conshohocken, PA, USA, 2015; Volume 1999, pp. 1-6.

52. Adewumi, A.A.; Ariffin, M.A.M.; Yusuf, M.O.; Maslehuddin, M.; Ismail, M. Effect of sodium hydroxide concentration on strength and microstructure of alkali-activated natural pozzolan and limestone powder mortar. Constr. Build. Mater. 2021, $271,121530$. [CrossRef] 